Revista Brasil. Bot., V.27, n.2, p.291-309, abr.-jun. 2004

\title{
Variações estruturais do compartimento arbóreo de uma floresta semidecídua alto-montana na chapada das Perdizes, Carrancas, MG
}

\author{
ARY T. OLIVEIRA FILHO ${ }^{1}$, DOUGLAS A. CARVALHO ${ }^{2}$, MARCO AURÉLIO L. FONTES $^{2}$, \\ EDUARDO VAN DEN BERG ${ }^{3}$, NILTON CURI $^{3}$ e WARLEY A.C. CARVALHO ${ }^{2}$
}

(recebido: 27 de junho de 2003; aceito: 29 de fevereiro de 2004)

\begin{abstract}
Structural variations of the arboreal component of a tropical upper montane semideciduous forest in the Perdizes Plateau, Carrancas, SE Brazil). The tree community of an area of upper montane forest situated in the Perdizes Plateau, SE Brazil (21 $36^{\prime}$ 'S and $44^{\circ} 37^{\prime} \mathrm{W}$ ), was surveyed with the purpose of assessing the correlations between their structural variations and environmental variables related to the substratum and edge effect. Variations were analyzed for physiognomic structure (tree density, basal area and size distribution) and community structure (species composition, distribution and diversity). Individual trees with diameter at breast height $(\mathrm{dbh}) \geq 5 \mathrm{~cm}$ were surveyed within 30 plots of $20 \times 20 \mathrm{~m}$ where topographic data and samples of surface soil were also collected, the latter for chemical and textural analyses. The survey totaled 2,565 individual trees, 218 species, 116 genera and 55 families, on three soil classes: Litholic Neosols, Humic Cambisols, and Regolithic Neosols. The studied tree community corresponds to the floristic and physiognomic features of the upper montane forests of southeastern Brazil, differing from those of lower altitudes in the same region. Variations in species diversity and composition and in physiognomic structure showed correlations with environmental variables, making up two distinct vegetation formations: (a) a less diverse and taller tree community in the well-drained areas of the forest interior, corresponding to the Humic Cambisols and Regolithic Neosols; and (b) a more diverse and shorter tree community in the strongly drained and sloping areas of the forest edge which correspond to the Litholic Neosols. The presumably more heterogeneous environment of the forest edge is probably responsible for its higher species diversity.
\end{abstract}

Key words - edge-effect, species diversity, species-environment relationship, tree community, tropical montane semideciduous forest

RESUMO - (Variações estruturais do compartimento arbóreo de uma floresta semidecídua alto-montana na chapada das Perdizes, Carrancas, MG). Realizou-se o levantamento da comunidade arbórea de uma floresta semidecídua alto-montana

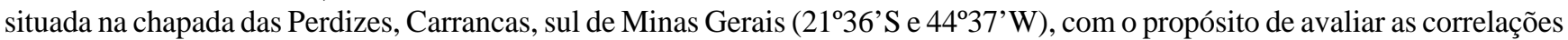
entre variações estruturais e variáveis ambientais relacionadas ao substrato e ao efeito borda. Foram analisados aspectos da estrutura fisionômica (densidade, área basal, e distribuição de tamanhos das árvores) e comunitária (composição, distribuição e diversidade de espécies). Foram alocadas 30 parcelas de $20 \times 20 \mathrm{~m}$ para amostragem dos indivíduos arbóreos com diâmetro à altura do peito $(\mathrm{DAP}) \geq 5 \mathrm{~cm}$, onde também foram coletados dados topográficos e amostras de solo superficial para análises químicas e texturais. Foram registrados 2.565 indivíduos, 217 espécies, 116 gêneros e 55 famílias, em três subgrupos de solos: Neossolos Litólicos, Cambissolos Húmicos e Neossolos Regolíticos. A comunidade arbórea estudada corresponde ao perfil florístico e fisionômico das florestas alto-montanas do sudeste brasileiro, diferenciando-se daquelas de menores altitudes da mesma região. As variações da diversidade e composição de espécies e da estrutura fisionômica mostraram correlações com variações ambientais, compondo duas formações vegetais distintas: (a) uma comunidade arbórea menos diversa e de maior porte em áreas bem drenadas de Cambissolos Húmicos e Neossolos Regolíticos, formando o interior da floresta; e (b) uma comunidade arbórea mais diversa e de menor estatura em sítios fortemente drenados e declivosos da borda da floresta, os quais correspondem aos Neossolos Litólicos. Presume-se que a maior heterogeneidade ambiental das bordas seja responsável por sua maior diversidade de espécies.

Palavras-chave -comunidade arbórea, diversidade de espécies, efeito borda, floresta semidecídua alto-montana, relações espécie-ambiente

\section{Introdução}

As florestas de montanha que abrigam nascentes de cursos d'água são importantes na manutenção da

1. Universidade Federal de Lavras, Departamento de Ciências Florestais, 37200-000 Lavras, MG, Brasil.

2. Universidade Federal de Lavras, Departamento de Biologia, 37200-000 Lavras, MG, Brasil.

3. Universidade Federal de Lavras, Departamento de Ciências do Solo, 37200-000 Lavras, MG, Brasil. qualidade e quantidade da água, além de proporcionarem condições para a sobrevivência da fauna regional. Atividades antrópicas como fogo, agricultura e pecuária, entre outras, têm proporcionado ao longo dos anos uma redução na área dessas florestas no Sudeste do Brasil, estando a maioria delas reduzidas a fragmentos de tamanhos bastante variáveis. Ações visando a sua proteção e recuperação fazem parte das estratégias de uma nova ordem de pensamento que visa garantir o 
suprimento de água, fonte primária da sobrevivência humana. Na região Sudeste, boa parte dessas florestas localiza-se em altitudes elevadas do complexo montanhoso e são ainda muito raras as descrições florísticas, estruturais e ecológicas de florestas situadas acima dos $1.400 \mathrm{~m}$ de altitude (e.g. Robim et al. 1990, para a flora de Campos do Jordão).

Ao sul do estado de Minas Gerais, na região do Alto Rio Grande, estudos envolvendo as formações florestais ripárias protetoras de nascentes (Oliveira Filho et al. 1994a, b, c, Vilela et al. 1994, 1995, van den Berg \& Oliveira Filho 1999, 2000) e aquelas localizadas ao longo do curso dos rios (Gavilanes et al. 1992, Oliveira Filho et al. 1994c, d, e, Carvalho et al. 1995a, b, Vilela et al. 2000, Botrel et al. 2002, Rodrigues et al. 2003, Souza et al. 2003) vêm sendo realizados, a partir de 1990, por meio do contrato firmado entre a Companhia Energética de Minas Gerais (CEMIG) e a Universidade Federal de Lavras (UFLA) e, entre 1998 e 2002, do Projeto de Conservação e Utilização Sustentável da Diversidade Biológica Brasileira (PROBIO).

O presente trabalho foi conduzido em um fragmento de floresta semidecídua alto-montana que protege uma das nascentes do rio Capivari, na chapada das Perdizes, município de Carrancas, MG, área esta considerada como uma das mais importantes para a conservação da biodiversidade no estado (Costa et al. 1998). O objetivo foi verificar as correlações entre as variações da estrutura do compartimento arbóreo da floresta e variáveis ambientais relacionadas ao substrato e efeito borda. Os aspectos estruturais analisados referem-se tanto à estrutura fisionômica (densidade, área basal, e distribuição de alturas e diâmetros das árvores) como à estrutura comunitária (composição, distribuição e diversidade de espécies). Compreende-se como substrato o conjunto de variáveis topográficas e edáficas determinantes do status nutricional mineral do solo e de seu regime hídrico. O efeito borda compreende o conjunto de variáveis ambientais (luz, umidade, ventos, etc.) condicionados pela proximidade da borda do fragmento (Murcia 1995).

\section{Material e métodos}

A área estudada corresponde a um fragmento de aproximadamente 36 ha de floresta semidecídua altomontana (sensu Oliveira Filho \& Fontes 2000, modificado de Veloso et al. 1991). Localiza-se na chapada das Perdizes, município de Carrancas, MG, nas coordenadas de $21^{\circ} 36^{\prime} \mathrm{S}$ e $44^{\circ} 37^{\prime} \mathrm{W}$ e a uma altitude que varia de $1.440 \mathrm{a} 1.513 \mathrm{~m}$. A floresta ocupa um fundo de vale que abriga uma das nascentes do rio Capivari, afluente do rio Grande, e apresenta bordas abruptas nos seus limites com o campo de altitude, que é a vegetação predominante do alto da chapada. De acordo com Pereira (2003), o clima é do tipo Cwa de Köppen; a temperatura média anual é de $14,8^{\circ} \mathrm{C}$, com médias mensais variando de $11,5^{\circ} \mathrm{C}$ em julho a $17,4{ }^{\circ} \mathrm{C}$ em janeiro; a precipitação média anual é de $1.483 \mathrm{~mm}$, com médias mensais variando de $246 \mathrm{~mm}$, no trimestre mais chuvoso (dezembro a fevereiro), a $24 \mathrm{~mm}$, no mais seco (junho a agosto).

A comunidade arbórea foi amostrada em 30 parcelas de $20 \times 20 \mathrm{~m}$, dispostas em três transeções (A-C), totalizando 1,2 ha de área amostrada (figura 1). As transeções foram concebidas de forma a representarem, a espaços regulares de $80 \mathrm{~m}$, três amostras das variações presumidas para a vegetação e para o ambiente entre duas bordas opostas da floresta e cruzando as duas encostas que flanqueiam o riacho. Em cada transeção, foram dispostas parcelas espaçadas a intervalos de $20 \mathrm{~m}$, exceto na extremidade norte, onde a última parcela de cada transeção foi ajustada à borda da floresta, ficando uma delas (A09) desalinhada para leste, com o propósito de se evitar um afloramento rochoso íngreme. As transeções A e B ficaram com 9 parcelas cada e a transeção C com 12 .

Um levantamento topográfico foi realizado na área, com auxílio de trena, bússola e clinômetro, a partir do qual foi produzida uma representação tridimensional da área (figura 1a) e foram extraídas três variáveis topográficas por parcela: (a) distância vertical até o riacho, obtida da diferença entre a cota média dos quatro vértices da parcela e a cota do riacho na transeção; (b) desnível, obtido da diferença entre as cotas máxima e mínima; e (c) declividade média, obtida da média da declividade dos quatro lados das parcelas. Estas foram obtidas como meio de avaliação indireta das condições hidrológicas dos solos, conforme adotado por Oliveira Filho et al. (1990, 1994d). Para avaliação do efeito borda na distribuição das espécies foi produzido um 'fator de borda' para cada parcela, de acordo com o método utilizado por Oliveira Filho et al. (1997). Este consiste do comprimento linear do contorno da borda medido entre dois (ou mais) pontos de intercessão com um círculo cujo raio tem origem no centro da parcela. O comprimento desse raio representaria o raio de ação máxima do efeito borda sobre a comunidade arbórea, tendo sido utilizado o mesmo valor de $100 \mathrm{~m}$ adotado por Espírito-Santo et al. (2002) e Souza et al. (2003) em fragmentos florestais da mesma região.

Os solos predominantes em cada parcela foram classificados no campo de acordo com o novo Sistema Brasileiro de Classificação dos Solos (Embrapa 1999), chegando até o nível de subgrupo (ou $4^{\circ}$ nível categórico) e incluindo as classes de drenagem. No centro de cada parcela, foram coletadas amostras simples do solo superficial (0-20 cm de profundidade) de cerca de 0,5 L. Efetuaram-se análises químicas e texturais das amostras no Laboratório de Análise de Solos da UFLA seguindo o protocolo da 
Embrapa (1997). As variáveis de solo obtidas foram: $\mathrm{pH}$; teores de $\mathrm{P}, \mathrm{K}, \mathrm{Ca}, \mathrm{Mg}, \mathrm{Al}, \mathrm{H}+\mathrm{Al}$; soma de bases (S.B.), saturação por bases (valor V); matéria orgânica e teores de areia, silte e argila. Após verificação gráfica da normalidade dos dados, as variáveis de solos e topografia foram comparadas entre as três classes de solos por meio de análises de variância, seguidas de testes de Tukey-Kramer, quando apropriado (Zar 1996).

Em cada parcela foram registrados todos os indivíduos arbóreos vivos e com circunferência à altura do peito (CAP) igual ou superior a $15,7 \mathrm{~cm}$, o que equivale a um diâmetro à altura do peito (DAP) de 5,0 cm. Os indivíduos com caules divididos desde a base foram incluídos no levantamento quando a área basal total dos caules correspondia a um CAS $\geq 15,7 \mathrm{~cm}$. Cada indivíduo foi marcado com etiqueta de alumínio numerada, sendo registrados seu número, a espécie, o valor dos CAPs, medido com fita métrica, e a altura total, estimada com auxílio de vara graduada. Foram coletadas amostras de material botânico dos espécimes registrados nas parcelas para posterior identificação. A identificação do material botânico foi realizada com a utilização de coleções botânicas já existentes no Herbário ESAL e também por

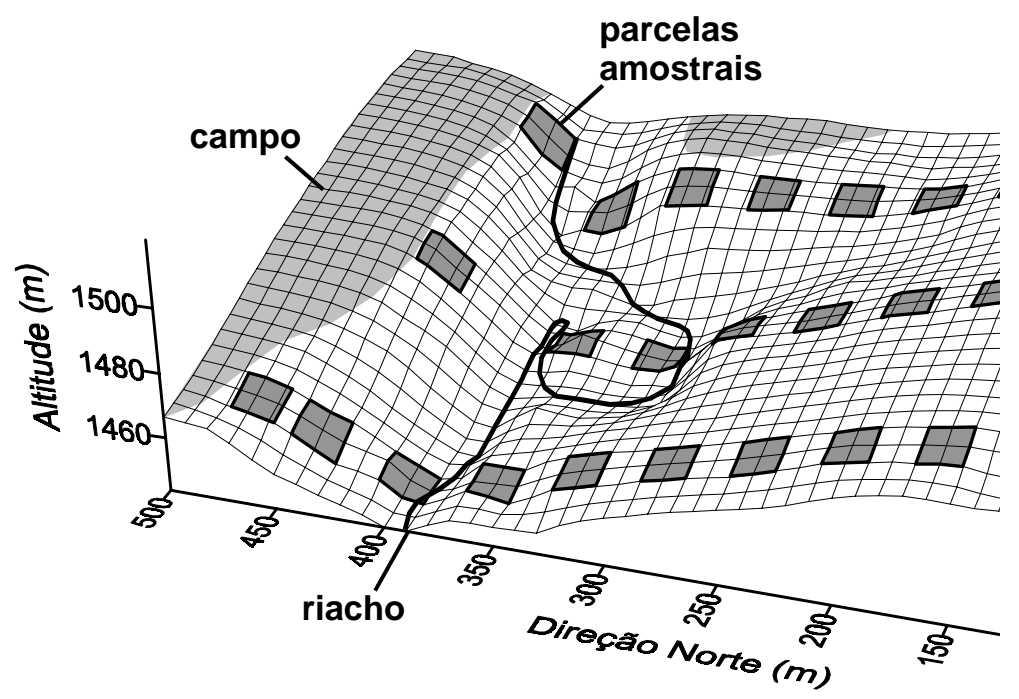

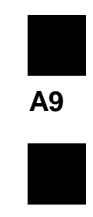

B9

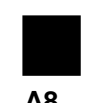

A8
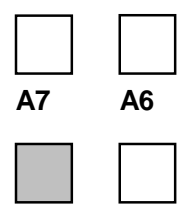

B7

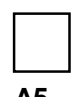

A5

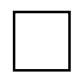

B5

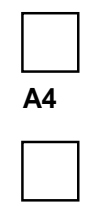

B4

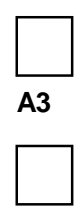

B3
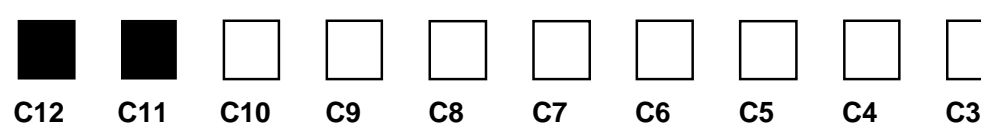

\section{CLASSES DE SOLO:

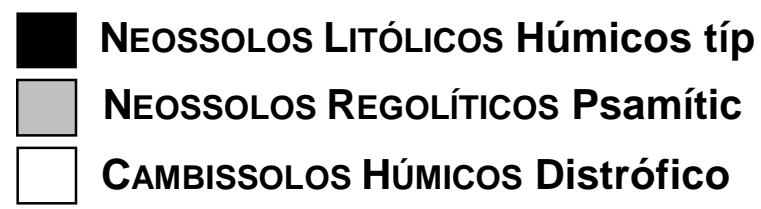

Figura 1. A. Grade de superfície mostrando a topografia da área de floresta semidecídua alto-montana e de campo de altitude estudada na chapada das Perdizes, Carrancas, MG, e a distribuição das três transeções amostrais, A, B e C, e de suas parcelas de $20 \times 20 \mathrm{~m}$. O espaçamento entre as linhas da grade é de $10 \mathrm{~m}$. B. Distribuição das classes de solo nas parcelas amostrais.

Figure 1. A. Surface gridline showing the topography of the area of tropical upper montane semideciduous forest and montane grassland studied in the "Chapada das Perdizes", Carrancas, SE Brazil, and the distribution of the three sample transects, A, B and C, and their $20 \times 20 \mathrm{~m}$ plots. Gridlines are spaced at $10 \mathrm{~m}$ intervals. B. Distribution of soil classes on sample plots. 
meio de consultas à literatura, a especialistas e a coleções dos Herbários do Jardim Botânico do Rio de Janeiro (RB), Instituto de Botânica de São Paulo (SP) e Universidade Estadual de Campinas (UEC). A coleção testemunha foi incorporada ao acervo do Herbário do Departamento de Biologia da Universidade Federal de Lavras (Herbário ESAL). As espécies foram classificadas nas famílias reconhecidas pelo sistema do Angiosperm Phylogeny Group II (APG II 2003).

Foram preparadas distribuições de densidade de árvores por classes de diâmetro e altura para as três classes de solo. No caso dos diâmetros, foram empregados intervalos de classe com amplitudes crescentes para compensar o forte decréscimo da densidade nas classes de tamanho maiores, típico da distribuição em J-invertido. Esses intervalos permitem uma melhor representação das classes diamétricas maiores e de baixa densidade, o que é desejável em comparações gráficas (Oliveira Filho et al. 2001). Após verificação gráfica da normalidade dos dados, as variáveis área basal, densidade total de árvores e densidade por classe de diâmetro e altura foram comparadas entre as três classes de solos por meio de análises de variância, seguidas de testes de Tukey-Kramer (Zar 1996).

A estrutura da comunidade arbórea foi descrita a partir do cálculo dos seguintes parâmetros quantitativos por espécie: altura máxima, número de indivíduos, número de parcelas com ocorrência da espécie, área basal e valor de cobertura (VC), este último obtido da soma dos valores relativos de número de indivíduos e área basal (Rodrigues 1988).

Para a determinação da diversidade de espécies foram calculados os índices de diversidade de Shannon $\left(H^{\prime}\right)$ e de eqüabilidade de Pielou $\left(J^{\prime}\right)$ em base logarítmica natural (Brower \& Zar 1984) para a amostra total e subamostras das três classes de solos. Os valores de $H^{\prime}$ obtidos para duas das classes de solos mais representativas foram comparados pelo teste de $t$ de Hutcheson (Zar 1996). Para se evitar o problema causado por diferentes intensidades amostrais em comparações entre índices, foi extraída aleatoriamente uma subamostra de dez parcelas por subgrupo de solo.

Para analisar as correlações entre os gradientes ambientais e vegetacionais foi empregada uma análise de correspondência canônica (CCA) (ter Braak 1987) utilizando o programa PC-ORD for Windows versão 4.14 (McCune \& Mefford 1999). A matriz de abundância das espécies foi constituída do número de indivíduos por parcela das 47 espécies que apresentaram dez ou mais indivíduos na amostra total. De acordo com as recomendações de ter Braak (1995), os valores de abundância foram transformados pela expressão $\log _{10}(\mathrm{a}+1)$ para compensar os desvios causados por alguns poucos valores muito elevados. Os subgrupos de solo foram discriminados no diagrama de ordenação das parcelas para facilitar a interpretação dos padrões emergentes.

A matriz de variáveis ambientais incluiu, a princípio, as três variáveis topográficas, o fator borda, a classe de drenagem dos solos, além de todas 13 variáveis químicas e texturais dos solos, totalizando 18 variáveis. As classes de drenagem dos solos foram expressas como variável ordinal ('ranking'), atribuída às categorias descritas pela Embrapa (1999): 4 - moderadamente drenado, 5 - bem drenado e 7 fortemente drenado (outras classes de drenagem não foram representadas). Após realizar uma CCA preliminar, foram eliminadas 11 variáveis ambientais fracamente correlacionadas ou altamente redundantes com outras variáveis. A CCA final foi processada com as sete variáveis mais representativas e mais fortemente correlacionadas com os eixos de ordenação: classe de drenagem; $\mathrm{pH}$, teores de fósforo e de argila do solo; fator borda, desnível e distância vertical até o riacho.

\section{Resultados}

Variáveis topográficas e edáficas - As três classes de solos identificadas no trecho de floresta ripária (figura 1B) foram: (a) os Cambissolos Húmicos Distróficos típicos, que são bem drenados, localizam-se no interior da floresta e foram representados em 18 parcelas; (b) os Neossolos Litólicos Húmicos típicos, que são fortemente drenados, localizam-se na borda da floresta, onde o relevo é mais acentuado e foram representados por 10 parcelas; e (c) os Neossolos Regolíticos Psamíticos lépticos, que são moderadamente drenados e se situam no interior de uma curva do riacho na altura da transeção $B$, onde há deposição de sedimentos principalmente de natureza coluvial. A partir desse ponto, as três classes de solo são referidas apenas pelos dois primeiros nomes.

As variáveis topográficas não diferiram significativamente entre as parcelas correspondentes às três classes de solo, com exceção da distância vertical, mais elevada nos Neossolos Regolíticos que nos Cambissolos Húmicos. A maioria das variáveis químicas e texturais dos solos diferiu significativamente entre as três classes de solo; as exceções foram $\mathrm{P}, \mathrm{K}, \mathrm{Mg}$ e silte (tabela 1). Contudo, a maior parte das diferenças foi detectada em comparações com os Neossolos Regolíticos, que foram representados por apenas duas amostras e se destacaram particularmente pela elevada saturação por bases. As duas classes de solo mais representativas, Cambissolos Húmicos e Neossolos Litólicos, diferiram significativamente apenas no teor de matéria orgânica, mais elevado nos primeiros, e pH, mais elevado nos últimos.

Florística, estrutura e diversidade da comunidade arbórea - Foram identificadas 218 espécies pertencentes a 116 gêneros e 55 famílias (tabela 2). Destacou-se a família Myrtaceae com 34 espécies, seguida de Melastomataceae 
Tabela 1. Variáveis topográficas das parcelas e variáveis químicas e texturais das amostras do solo superficial (0-20 cm de profundidade) obtidas nas 30 parcelas empregadas para amostrar a floresta semidecídua altimontana da chapada das Perdizes, Carrancas, MG. Os valores são médias \pm desvios padrão das $N$ amostras de cada uma das três classes de solo. Nos casos em que os testes de $F$ indicaram diferenças significativas entre as classes de solo, médias seguidas da mesma letra não diferiram significativamente entre si pelo teste de Tukey $(P \leq 0.05)$.

Table 1. Topographical variables of sample plots and chemical and textural variables of surface soil samples $(0-20 \mathrm{~cm}$ of depth) obtained in the 30 plots used to sample the tropical upper montane semideciduous forest in the Chapada das Perdizes, Carrancas, SE Brazil. Values are means \pm standard deviations of $N$ samples of the three soil classes. Where $F$-tests yielded significant differences among soils classes, means followed by the same lower case letter did not differ significantly in Tukey-tests $(P \leq 0.05)$.

\begin{tabular}{|c|c|c|c|c|c|}
\hline \multirow[b]{2}{*}{ Variáveis } & \multirow{2}{*}{$\begin{array}{l}\text { Cambissolos Húmicos } \\
\qquad(N=18)\end{array}$} & \multirow{2}{*}{$\begin{array}{l}\text { Neossolos Litólicos } \\
\qquad(N=10)\end{array}$} & \multirow{2}{*}{$\begin{array}{l}\text { Neossolos Regolíticos } \\
\qquad(N=2)\end{array}$} & \multicolumn{2}{|c|}{ ANOVA } \\
\hline & & & & $F$ & $P$ \\
\hline Cota média (m) & $1478,1 \pm 15,1$ & $1484,8 \pm 8,6$ & $1454,0 \pm 0,7$ & 3,07 & 0,06 \\
\hline Distância vertical até o rio (m) & $27,0 \pm 12,3^{\mathbf{a b}}$ & $32,4 \pm 19,7^{\mathrm{a}}$ & $1,0 \pm 0,0^{\mathbf{b}}$ & 3,66 & 0,03 \\
\hline Desnível (m) & $5,5 \pm 1,5$ & $8,1 \pm 4,5$ & $5,8 \pm 1,5$ & 2,67 & 0,09 \\
\hline Declividade média (graus) & $15,3 \pm 4,0$ & $21,3 \pm 10,6$ & $16,0 \pm 4,0$ & 2,42 & 0,11 \\
\hline $\mathrm{pH}$ em $\mathrm{H}_{2} \mathrm{O}$ & $4,0 \pm 0,1^{\mathbf{b}}$ & $4,3 \pm 0,3^{a}$ & $4,2 \pm 0,1^{\mathbf{a b}}$ & 5,64 & 0,09 \\
\hline $\mathrm{P}-$ Mehlich $\left(\mathrm{mg} \cdot \mathrm{dm}^{3}\right)$ & $3,8 \pm 0,8$ & $3,1 \pm 1,4$ & $4,5 \pm 0,7$ & 2,45 & 0,11 \\
\hline $\mathrm{K}^{+}\left(\mathrm{mg} \cdot \mathrm{dm}^{-3}\right)$ & $51 \pm 14$ & $63 \pm 23$ & $79 \pm 32$ & 2,68 & 0,09 \\
\hline $\mathrm{Ca}^{++}\left(\right.$cmolc. $\left.\mathrm{dm}^{-3}\right)$ & $0,3 \pm 0,1^{\mathbf{a b}}$ & $0,3 \pm 0,1^{\mathbf{b}}$ & $0,4 \pm 0,0^{\mathrm{a}}$ & 3,77 & 0,04 \\
\hline $\mathrm{Mg}^{++}\left(\mathrm{cmolc} . \mathrm{dm}^{-3}\right)$ & $0,1 \pm 0,0$ & $0,1 \pm 0,0$ & $0,1 \pm 0,0$ & 0,32 & 0,73 \\
\hline $\mathrm{Al}^{+++}\left(\mathrm{cmolc} \cdot \mathrm{dm}^{-3}\right)$ & $3,7 \pm 0,6^{\mathrm{a}}$ & $3,0 \pm 1,2^{\mathbf{a b}}$ & $1,7 \pm 0,3^{\mathbf{b}}$ & 7,00 & 0,004 \\
\hline $\mathrm{H}^{+}+\mathrm{Al}^{+++}\left(\mathrm{cmolc} \cdot \mathrm{dm}^{-3}\right)$ & $21,0 \pm 3,7^{\mathrm{a}}$ & $17,5 \pm 6,8^{\mathbf{a b}}$ & $9,7 \pm 3,7^{\mathbf{b}}$ & 5,42 & 0,01 \\
\hline SB - soma de bases $\left(\right.$ cmolc. $\left.\mathrm{dm}^{-3}\right)$ & $0,5 \pm 0,1^{\mathbf{a b}}$ & $0,5 \pm 0,1^{\mathbf{b}}$ & $0,7 \pm 0,1^{\mathbf{a}}$ & 3,23 & 0,05 \\
\hline V - saturação p/bases (\%) & $2,6 \pm 0,6^{\mathbf{b}}$ & $3,3 \pm 1,4^{\mathbf{b}}$ & $7,1 \pm 1,8^{\mathrm{a}}$ & 19,21 & $10^{-5}$ \\
\hline Matéria orgânica (dag.kg-1) & $6,8 \pm 1,7^{\mathrm{a}}$ & $4,9 \pm 1,3^{\mathbf{b}}$ & $3,1 \pm 1,0^{\mathbf{b}}$ & 9,04 & 0,001 \\
\hline Areia $(\%)$ & $61,7 \pm 6,8^{b}$ & $65,4 \pm 9,3^{\mathbf{a b}}$ & $80,0 \pm 8,5^{\mathrm{a}}$ & 5,18 & 0,01 \\
\hline Silte $(\%)$ & $12,9 \pm 5,2$ & $13,9 \pm 9,6$ & $7,5 \pm 4,9$ & 0,69 & 0,51 \\
\hline Argila (\%) & $25,4 \pm 4,0^{\mathrm{a}}$ & $20,7 \pm 7,2^{\mathbf{a b}}$ & $12,5 \pm 3,5^{b}$ & 6,85 & 0,004 \\
\hline
\end{tabular}

(24), Lauraceae (18), Asteraceae e Rubiaceae (nove), Aquifoliaceae e Myrsinaceae (sete), Euphorbiaceae e Clusiaceae (seis) e Annonaceae, Cyatheaceae, Solanaceae e Fabaceae (cinco), representando 64,5\% das espécies. Os gêneros com maiores números de espécies foram Miconia (15), Myrcia e Ocotea (nove), Ilex (sete), Myrsine e Tibouchina (seis), Eugenia (cinco), Calyptranthes, Cyathea, Nectandra, Siphoneugena (quatro), Aspidosperma, Croton, Gomidesia, Mollinedia, Myrciaria, Persea, Solanum e Vitex (três), que juntos, contribuíram com 44,7\% das espécies.

Foram amostrados 2.565 indivíduos de 132 espécies. Dez famílias contribuíram com 75,2\% do número total de indivíduos, com Lauraceae ocupando a primeira posição $(17,7 \%)$, seguida de Myrtaceae (13,9\%), Rubiaceae (10,3\%), Melastomataceae $(7,2 \%)$, Apocynaceae $(6,0 \%)$, Euphorbiaceae $(5,2 \%)$, Myrsinaceae (5,1\%), Asteraceae (4,5\%), Annonaceae $(2,9 \%)$ e Araliaceae $(2,5 \%)$. As sete espécies mais abundantes totalizaram 39,0\% do número total de indivíduos, destacando-se Ocotea odorifera $(7,9 \%)$, Psychotria sessilis (7,1\%), Aspidosperma parvifolium (6,0\%), Nectandra grandiflora (5,3\%), Miconia chartacea $(4,8 \%)$, Eremanthus erythropappus $(4,0 \%)$ e Myrsine umbellata (3,9\%). Na estratificação da comunidade observou-se que um elevado número de espécies atingiu estaturas elevadas: 45 delas registraram alturas máximas $\geq 20 \mathrm{~m}$.

O índice de diversidade de Shannon $\left(H^{\prime}\right)$ e o índice de equiabilidade de Pielou ( $\left.J^{\prime}\right)$ para a amostra total foram de 3,92 nats.indivíduo ${ }^{-1}$ e 0,80 (tabela 3). Foi significativa a diferença entre os valores de $H^{\prime}$ das subamostras correspondentes às duas classes de solo predominantes ( $t$ de Hutcheson $=2,42, P<0,01$ ), sendo mais alto para os Neossolos Litólicos que para os Cambissolos Húmicos. Como os valores de $J$ ' são muito próximos para as duas classes de solo, esta diferença está provavelmente vinculada mais fortemente à riqueza 
Tabela 2. Espécies arbóreas registradas na floresta semidecídua altimontana da chapada das Perdizes, Carrancas, MG, dispostas em ordem alfabética de famílias botânicas e acompanhadas de seus respectivos números de registro (Rg) no Herbário ESAL e parâmetros quantitativos obtidos na amostra de 30 parcelas de $20 \times 20 \mathrm{~m}: \mathrm{h}=$ altura máxima, $\mathrm{N}=$ número de indivíduos, $\mathrm{P}=$ número de parcelas com ocorrência da espécie, $\mathrm{AB}=$ área basal, e $\mathrm{VC}$ = valor de cobertura. Espécies com $\mathrm{N}=$ 'Flora' foram registradas apenas fora das parcelas amostrais.

Table 2. Tree species registered in the tropical upper montane forest of the Chapada das Perdizes, Carrancas, SE Brazil, ordered alphabetically per botanical family and followed by their respective registration number (Rg) in the ESAL Herbarium and quantitative parameters obtained in the sample of $3020 \times 20 \mathrm{~m}$ plots: $\mathrm{h}=$ maximum height; $\mathrm{N}=$ number individuals; $\mathrm{P}=$ number of plots with the species, $\mathrm{AB}=$ basal area, and $\mathrm{VC}=$ cover value. Species with $\mathrm{N}=$ ' $\mathrm{F}$ ' were registered only outside sample plots.

\begin{tabular}{llllllll}
\hline Famílias/Espécies & $\mathrm{Rg}$ & $\mathrm{h}$ & $\mathrm{h}$ & $\mathrm{P}$ & $\begin{array}{l}\mathrm{AB} \\
\left(\mathrm{m}^{2}\right)\end{array}$ & $\mathrm{VC}$ \\
\hline
\end{tabular}

\section{ANACARDIACEAE}

Tapirira guianensis Aublet

Tapirira obtusa (Benth.) Mitchell

ANNONACEAE

Annona cacans Warm.

Guatteria australis A. St.-Hil.

Guatteria nigrescens Mart.

Rollinia dolabripetala (Raddi) R.E. Fries

Xylopia brasiliensis Sprengel

APOCYNACEAE

Aspidosperma cylindrocarpon Müll. Arg.

Aspidosperma parvifolium A. DC.

Aspidosperma spruceanum Benth.

12170
12330
14937
16120
14871
12221
12137
15763
14867
12958

16225
16222
16223
16224
16226
12840
16227

\section{0,0}

21,0

1

28

1

0,003

0,05

\section{2,0}

25,0

6

12

0,542

2,41

25,0

22

4

0,207

0,73

16

0,379

1,78

17

0,964

4,10

$\mathrm{F}$

F

AQUIFOLIACEAE

Ilex amara (Vell.) Loes.

Ilex brevicuspis Reissek

Ilex cerasifolia Reissek

Ilex conocarpa Reissek

Ilex paraguariensis A. St.-Hil.

15,0

32,0

2
153
$\mathrm{~F}$

0,049

0,20

5,350

19,01

Ilex sapotifolia Reissek

Ilex theezans Mart.

ARALIACEAE

Schefflera angustissima (E. Marchal) D. Frodin

16712

Schefflera calva (Cham.) D. Frodin

15490

14,0

14,0

14,0

20,0

8,0

12333

Euterpe edulis Mart.

15165

F

5

6

11

3

0,061

0,099

0,34

0,156

0,47

3

0,004

0,81

0,05

Geonoma schottiana Mart.

ASTERACEAE

Dasyphyllum brasiliense (Sprengel) Cabrera

10742

Dasyphyllum spinescens (Less.) Cabrera

17668

Eremanthus erythropappus (DC.) MacLeish

16228

Eremanthus incanus (Less.) Less.

14860

Eupatorium vauthierianum DC.

16229

Eupatorium velutinum Gardner

16230

Gochnatia paniculata (Less.) Cabrera

15151

Piptocarpha macropoda Baker

16231

Vernonanthura diffusa (Less.) H. Robinson

BIGNONIACEAE

Jacaranda subalpina W. Morawetz

Tabebuia alba (Cham.) Sandw.

16232

16233

16234

Cordia sellowiana Cham.

12347

$\begin{array}{rr} & \mathrm{F} \\ 6,0 \quad 42\end{array}$

17

0,106

1,90

0,11

6,84

$\begin{array}{ll}0,030 & 0,11 \\ 1,796 & 6,84\end{array}$

$\begin{array}{rr} & F \\ & F \\ 13,0 \quad 103\end{array}$

6,0

18,0

26,0

17,0

15,0

18,0

4

4
29

6

2,247

9,50

1

0,002

0,05

$\begin{array}{ll}0,082 & 0,36 \\ 0,374 & 1,22\end{array}$

$\begin{array}{ll}2 & 0,082 \\ 6 & 0,374\end{array}$

1,22

1,12

$\begin{array}{ll}8 & 0,281 \\ 4 & 0,147\end{array}$

0,52

2,25 
continuação

\begin{tabular}{|c|c|c|c|c|c|c|}
\hline Famílias/Espécies & $\operatorname{Rg}$ & $\begin{array}{l}\mathrm{h} \\
(\mathrm{m})\end{array}$ & $\mathrm{N}$ & $\mathrm{P}$ & $\begin{array}{l}\mathrm{AB} \\
\left(\mathrm{m}^{2}\right)\end{array}$ & $\mathrm{VC}$ \\
\hline \multicolumn{7}{|l|}{ BURSERACEAE } \\
\hline Protium widgrenii Engler & 12159 & 5,0 & 1 & 1 & 0,004 & 0,05 \\
\hline \multicolumn{7}{|l|}{ CANELLACEAE } \\
\hline Cinnamodendron dinisii Schwacke & 16402 & & $\mathrm{~F}$ & & & \\
\hline \multicolumn{7}{|l|}{ CELASTRACEAE } \\
\hline Maytenus salicifolia Reissek & 14894 & 10,0 & 13 & 4 & 0,081 & 0,71 \\
\hline Tontelea leptophylla A.C. Smith & 16244 & & $\mathrm{~F}$ & & & \\
\hline \multicolumn{7}{|l|}{ CHLORANTHACEAE } \\
\hline Hedyosmum brasiliense Mart. & 15170 & & $\mathrm{~F}$ & & & \\
\hline \multicolumn{7}{|l|}{ CLETHRACEAE } \\
\hline Clethra scabra Pers. & 14890 & 13,0 & 11 & 2 & 0,167 & 0,84 \\
\hline \multicolumn{7}{|l|}{ CLUSIACEAE } \\
\hline Calophyllum brasiliense Cambess. & 12384 & & $\mathrm{~F}$ & & & \\
\hline Clusia criuva Cambess. & 16236 & 5,0 & 1 & 1 & 0,002 & 0,05 \\
\hline Garcinia gardneriana (Planchon \& Triana) Zappi & 16237 & 15,0 & 6 & 6 & 0,053 & 0,36 \\
\hline Tovomitopsis saldanhae Engler & 16238 & 22,0 & 22 & 12 & 0,333 & 1,67 \\
\hline Vismia brasiliensis Choisy & 15164 & 8,0 & 4 & 2 & 0,022 & 0,21 \\
\hline Vismia parviflora Cham. \& Schltdl. & 16507 & & $\mathrm{~F}$ & & & \\
\hline \multicolumn{7}{|l|}{ CUNONIACEAE } \\
\hline Lamanonia cuneata (Cambess.) O. Kuntze & 17089 & & $\mathrm{~F}$ & & & \\
\hline Lamanonia ternata Vell. & 13147 & 20,0 & 1 & 1 & 0,165 & 0,44 \\
\hline Weinmannia paulliniifolia Pohl & 15159 & & $\mathrm{~F}$ & & & \\
\hline \multicolumn{7}{|l|}{ CYATHEACEAE } \\
\hline Alsophila sternbergii (Sternb.) Conant & 14623 & 5,0 & 4 & 1 & 0,029 & 0,23 \\
\hline Cyathea corcovadensis (Raddi) Domin & 16240 & 6,0 & 3 & 3 & 0,066 & 0,28 \\
\hline Cyathea delgadii Sternb. & 13395 & 12,0 & 9 & 4 & 0,156 & 0,73 \\
\hline Cyathea phalerata Mart. & 15161 & 3,0 & 2 & 1 & 0,050 & 0,20 \\
\hline Cyathea rufa (Fée) Lellinger & 14624 & 3,0 & 1 & 1 & 0,005 & 0,05 \\
\hline \multicolumn{7}{|l|}{ ELAEOCARPACEAE } \\
\hline Sloanea monosperma Vell. & 14922 & 12,0 & 5 & 4 & 0,019 & 0,24 \\
\hline \multicolumn{7}{|l|}{ EUPHORBIACEAE } \\
\hline Alchornea triplinervea (Sprengel) Müll. Arg. & 15463 & 31,0 & 82 & 21 & 3,023 & 10,58 \\
\hline Croton floribundus Sprengel & 14879 & & $\mathrm{~F}$ & & & \\
\hline Croton salutaris Casar. & 16241 & & $\mathrm{~F}$ & & & \\
\hline Croton verrucosus Radcl.-Sm. \& Govaerts & 12361 & 29,0 & 3 & 3 & 0,144 & 0,47 \\
\hline Pera glabrata (Schott) Poepp. & 11078 & 28,0 & 46 & 21 & 1,116 & 4,51 \\
\hline Sapium glandulosum (L.) Morong & 14628 & & $\mathrm{~F}$ & & & \\
\hline \multicolumn{7}{|l|}{ FABACEAE } \\
\hline Dalbergia villosa (Benth.) Benth. & 15035 & 25,0 & 33 & 19 & 0,678 & 2,94 \\
\hline Inga sessilis (Vell.) Mart. & 15457 & 24,0 & 13 & 7 & 0,416 & 1,52 \\
\hline Inga vulpina Mart. & 13238 & & $\mathrm{~F}$ & & & \\
\hline Leucochloron incuriale (Vell.) Barneby \& Grimes & 16253 & 8,0 & 1 & 1 & 0,008 & 0,06 \\
\hline Machaerium villosum Vogel & 12425 & 8,0 & 1 & 1 & 0,023 & 0,10 \\
\hline \multicolumn{7}{|l|}{ HUMIRIACEAE } \\
\hline Humiria balsamifera (Aublet) A. St.-Hil. & 16245 & & $\mathrm{~F}$ & & & \\
\hline Humiriastrum glaziovii (Urban) Cuatrec. & 16713 & & $\mathrm{~F}$ & & & \\
\hline \multicolumn{7}{|l|}{ LAURACEAE } \\
\hline Cinnaтотит glaziovii (Mez) Vattimo & 16246 & 29,0 & 7 & 7 & 0,670 & 1,90 \\
\hline Cryptocarya aschersoniana $\mathrm{Mez}$ & 12419 & 24,0 & 5 & 4 & 0,478 & 1,36 \\
\hline Nectandra grandiflora Nees & 16247 & 28,0 & 135 & 24 & 1,446 & 8,79 \\
\hline Nectandra lanceolata Nees & 16248 & & $\mathrm{~F}$ & & & \\
\hline
\end{tabular}


continuação

Famílias/Espécies

$\operatorname{Rg}$

$\mathrm{h}$

$\mathrm{N}$

$\mathrm{P}$

(m)

$\mathrm{AB}$

$\left(\mathrm{m}^{2}\right)$

Nectandra membranacea (Swartz) Griseb.

15393

Nectandra oppositifolia Nees

Ocotea aciphylla (Nees) Mez

Ocotea brachybotra (Meisner) Mez

Ocotea corymbosa (Meisner) Mez

Ocotea diospyrifolia (Meisner) Mez

Ocotea elegans $\mathrm{Mez}$

Ocotea laxa (Nees) Mez

Ocotea odorifera (Vell.) Rohwer

Ocotea puberula (Rich.) Nees

Ocotea pulchella Mart.

12411

16249

16250

13140

16251

15399

16252

15047

17385

15403

Persea alba Nees \& Mart.

17388

Persea pyrifolia Nees \& Mart.

Persea rufotomentosa Nees \& Mart.

12398

17389

LOGANIACEAE

Strychnos brasiliensis (Sprengel) Mart.

\section{LYTHRACEAE}

Lafoensia densiflora Pohl

Lafoensia pacari A. St.-Hil.

15296

F

$28,0 \quad 28$

$13,0 \quad 3$

15

5
2

0,595

2,54

$\mathrm{F}$

$28,0 \quad 35$

$25,0 \quad 18$

24,0

11

$$
1,202
$$

4,29

13

0,426

1,74

F

$23,0 \quad 203$

20,0

1

9,0

7

$\mathrm{F}$

$25,0 \quad 10$

16254

07394

7,0

13,0

10193

Talauma ovata A. St.-Hil.

MALPIGHIACEAE

Byrsonima cuneifolia Griseb.

Byrsonima laxiflora Griseb.

15442

15441

$$
27,0
$$

12887

Leandra melastomoides Raddi

12239

Leandra scabra DC.

11637

Miconia chamissois Naudin

15439

17306

Miconia cinnamomifolia (DC.) Naudin

15437

Miconia corallina Sprengel

Miconia eichlerii Cogn.

Miconia fasciculata Gardner

Miconia latecrenata (DC.) Naudin

Miconia ligustroides (DC.) Naudin

Miconia minutiflora (Bonpl.) Triana

Miconia pepericarpa DC.

Miconia pusilliflora (DC.) Triana

Miconia sellowiana Naudin

Miconia theaezans (Bonpl.) Cogn

15436

15435

15100

16255

14061

15434

14060

12492

16256

09802

Miconia urophylla DC.

Tibouchina candolleana (DC.) Cogn.

16257

07869

Tibouchina fothergillae (DC.) Cogn.

Tibouchina moricandiana (DC.) Baillon

01765

10663

Tibouchina multiflora (Gardner) Cogn.

10603

16258

Tibouchina sellowiana (Cham.) Cogn.

13137

Tibouchina stenocarpa (DC.) Cogn.

15431

$\mathrm{F}$

Trembleya parviflora (D. Don) Cogn.

MELIACEAE

Cabralea canjerana (Vell.) Mart.

16259

$\begin{array}{rr} & F \\ 17,0 \quad 122\end{array}$

F

F

25

0,628

6,29

20,0

1

0,073

0,22

6,0

1

0,003

0,05

$\mathrm{F}$

F

$11,0 \quad 3$

3

0,026

0,18

$24,0 \quad 56$

17

0,424

$\begin{array}{cc} & \text { F } \\ & \text { F } \\ & \text { F } \\ & \text { F } \\ & 1 \\ & \text { F } \\ & \text { F }\end{array}$

$12,0 \quad 8$

8

0,069

0,48

continua 
continuação

\begin{tabular}{|c|c|c|c|c|c|c|}
\hline Famílias/Espécies & $\mathrm{Rg}$ & $\begin{array}{l}\mathrm{h} \\
(\mathrm{m})\end{array}$ & $\mathrm{N}$ & $\mathrm{P}$ & $\begin{array}{l}\mathrm{AB} \\
\left(\mathrm{m}^{2}\right)\end{array}$ & $\mathrm{VC}$ \\
\hline Trichilia emarginata (Turcz.) C. DC. & 15429 & & $\mathrm{~F}$ & & & \\
\hline \multicolumn{7}{|l|}{ MONIMIACEAE } \\
\hline Mollinedia argyrogyna Perkins & 12477 & 17,0 & 32 & 13 & 0,299 & 1,98 \\
\hline Mollinedia triflora (Sprengel) Tul. & 15427 & & $\mathrm{~F}$ & & & \\
\hline Mollinedia widgrenii A. DC. & 14589 & 8,0 & 2 & 2 & 0,009 & 0,10 \\
\hline \multicolumn{7}{|l|}{ MORACEAE } \\
\hline Ficus mexiae Standley & 16260 & 15,0 & 2 & 2 & 0,026 & 0,14 \\
\hline Sorocea bonplandii (Baillon) W.Burger & 15094 & 11,0 & 16 & 10 & 0,090 & 0,84 \\
\hline \multicolumn{7}{|l|}{ MYRSINACEAE } \\
\hline Cybianthus brasiliensis (Mez) Agostini & 16261 & 7,0 & 1 & 1 & 0,002 & 0,04 \\
\hline Myrsine coriacea (Swartz) R. Br. & 16262 & 7,0 & 1 & 1 & 0,011 & 0,07 \\
\hline Myrsine gardneriana A. DC. & 12894 & 18,0 & 28 & 11 & 0,127 & 1,40 \\
\hline Myrsine guianensis (Aublet) Kuntze & 16714 & & $\mathrm{~F}$ & & & \\
\hline Myrsine intermedia (Mez) Pipoly & 17621 & 13,0 & 6 & 5 & 0,027 & 0,30 \\
\hline Myrsine lancifolia Mart. & 12894 & & $\mathrm{~F}$ & & & \\
\hline Myrsine umbellata Mart. & 15257 & 20,0 & 100 & 18 & 0,725 & 5,67 \\
\hline \multicolumn{7}{|l|}{ MYRTACEAE } \\
\hline Blepharocalyx salicifolius (Kunth) O. Berg & 16263 & 4,0 & 1 & 1 & 0,002 & 0,04 \\
\hline Calyptranthes brasiliensis Sprengel & 14961 & 20,0 & 43 & 18 & 0,289 & 2,38 \\
\hline Calyptranthes clusiifolia (Miq.) O. Berg & 15524 & 23,0 & 9 & 8 & 0,062 & 0,50 \\
\hline Calyptranthes concinna DC. & 16264 & 26,0 & 49 & 17 & 0,308 & 2,66 \\
\hline Calyptranthes grandifolia O. Berg & 16265 & & $\mathrm{~F}$ & & & \\
\hline Eugenia excelsa $\mathrm{O}$. Berg & 16266 & 7,0 & 1 & 1 & 0,005 & 0,05 \\
\hline Eugenia handroana D. Legrand & 16267 & 9,0 & 5 & 2 & 0,049 & 0,31 \\
\hline Eugenia hyemalis Cambess. & 16268 & 19,0 & 46 & 18 & 0,682 & 3,45 \\
\hline Eugenia involucrata DC. & 16269 & 9,0 & 2 & 1 & 0,006 & 0,09 \\
\hline Eugenia punicifolia (Kunth) DC. & 15452 & 10,0 & 1 & 1 & 0,002 & 0,05 \\
\hline Gomidesia eriocalyx (DC.) O. Berg & 16270 & 8,0 & 2 & 2 & 0,005 & 0,09 \\
\hline Gomidesia palustris (DC.) D. Legrand & 16271 & & $\mathrm{~F}$ & & & \\
\hline Gomidesia tijucensis (Kiaersk.) D. Legrand & 15348 & & $\mathrm{~F}$ & & & \\
\hline Marlierea racemosa (Vell.) Kiaersk. & 16272 & & $\mathrm{~F}$ & & & \\
\hline Myrcia breviramis (O.Berg) D. Legrand & 16273 & & $\mathrm{~F}$ & & & \\
\hline Myrcia crassifolia (Miq.) Kiaersk. & 16274 & 3,5 & 1 & 1 & 0,003 & 0,05 \\
\hline Myrcia detergens Miq. & 15083 & 13,0 & 7 & 6 & 0,031 & 0,35 \\
\hline Myrcia eriopus DC. & 16275 & 6,5 & 1 & 1 & 0,003 & 0,05 \\
\hline Myrcia fallax (Rich.) DC. & 16276 & 13,0 & 4 & 4 & 0,010 & 0,18 \\
\hline Myrcia guianensis (Aublet) DC. & 16278 & 10,0 & 27 & 9 & 0,081 & 1,25 \\
\hline Myrcia laruotteana Cambess. & 12254 & & $\mathrm{~F}$ & & & \\
\hline Myrcia rostrata DC. & 12242 & 10,0 & 50 & 6 & 0,234 & 2,52 \\
\hline Myrcia venulosa DC. & 16277 & 26,0 & 43 & 17 & 0,722 & 3,44 \\
\hline Myrciaria cauliflora (Mart.) O. Berg & 15082 & 11,0 & 1 & 1 & 0,004 & 0,05 \\
\hline Myrciaria floribunda (West) O. Berg & 16279 & 18,0 & 37 & 19 & 0,108 & 1,70 \\
\hline Myrciaria tenella (DC.) O. Berg & 12252 & & $\mathrm{~F}$ & & & \\
\hline Pimenta pseudocaryophyllus (Gomes) Landrum & 16280 & 13,0 & 6 & 6 & 0,023 & 0,28 \\
\hline Plinia rivularis (Cambess.) Rotman & 16281 & & $\mathrm{~F}$ & & & \\
\hline Psidium cattleyanum Sabine & 12503 & 9,0 & 9 & 8 & 0,044 & 0,46 \\
\hline Psidium rufum Mart. & 16282 & 13,0 & 2 & 1 & 0,048 & 0,20 \\
\hline Siphoneugena densiflora O. Berg & 16283 & 6,0 & 1 & 1 & 0,004 & 0,05 \\
\hline Siphoneugena kiaerskoviana (Burret) Kausel & 15376 & & $\mathrm{~F}$ & & & \\
\hline Siphoneugena kuhlmannii Mattos & 12939 & 9,0 & 3 & 2 & 0,016 & 0,16 \\
\hline Siphoneugena widgreniana $\mathrm{O}$. Berg & 15712 & & $\mathrm{~F}$ & & & \\
\hline
\end{tabular}


continuação

Famílias/Espécies

$\mathrm{Rg}$

$\mathrm{h}$
$(\mathrm{m})$

$\mathrm{N}$

$\mathrm{P}$

$\mathrm{AB}$

$\left(\mathrm{m}^{2}\right)$

NYCTAGINACEAE

Guapira opposita (Vell.) Reitz

16284

30,0

55

17

1,085

4,79

OLACACEAE

Heisteria silvianii Schwacke

16285

25,0

3

3

0,048

0,24

PHYLLANTHACEAE

Hyeronima ferruginea Müll. Arg.

14479

Richeria grandis Vahl

16242

8,0

1

1

0,004

0,05

PICRAMNIACEAE

Picramnia glazioviana Engler

14944

F

PIPERACEAE

Piper caracolanum C. DC.

16286

F

PODOCARPACEAE

Podocarpus sellowii Klotzsch

PROTEACEAE

Euplassa itatiae Sleumer

Euplassa organensis (Gardner) Johnston

16287

16287

16288

16570

Roupala rhombifolia Mart.

15368

RHAMNACEAE

Rhamnus sphaerosperma Swartz

16290

ROSACEAE

Prunus brasiliensis (Cham. \& Schltdl.) D. Dietr.

Prunus myrtifolia (L.) Urban

15365

16291

RUBIACEAE

Alibertia elliptica (Cham.) K. Schum.

16292

12561

Amaioua guianensis Aublet

12555

Faramea cyanea Müll. Arg.

10037

Faramea multiflora A. Rich.

16293

Hillia parasitica Jacquin

Ixora gardneriana Benth.

Psychotria sessilis (Vell.) Müll. Arg.

16294

12544

Psychotria suterella Müll. Arg.

Rudgea jasminoides (Cham.) Müll. Arg.

16295

16296

16297

15473

Dictyoloma vandellianum A. Juss.

12565

Zanthoxylum rhoifolium Lam.

15471

Meliosma sinuata Urban

SALICACEAE

Casearia decandra Jacquin

Casearia obliqua Sprengel

15444

15385

Xylosma ciliatifolia (Clos) Eichler

16243

SAPINDACEAE

Cupania paniculata Cambess.

15447

SAPOTACEAE

Chrysophyllum marginatum (Hook. \& Arn.) Radlk.

SIPARUNACEAE

Siparuna cujabana (Mart.) A. DC.

SOLANACEAE

Aureliana velutina Sendt.

Cestrum schlechtendalii G. Don

15722

12473

$$
7,0
$$

1

1

0,037

0,13

\section{9,0}

6,0

26,0

1
1

1

0,009

0,015

0,06

$26,0 \quad 26$

12

0,787

2,93

$6,0 \quad 1$

1

0,003

0,05

7,0

16,0

1

0,003

0,05

5,0

28,0

74

1

1

0,182

1,27

0,004

0,05

$\begin{array}{r}28,0 \quad \mathrm{~F} \\ \hline\end{array}$

21

0,832

4,91

$\begin{array}{rr} & F \\ & F \\ & F \\ 15,0 & 183 \\ 3,0 & 5 \\ 8,0 & 1\end{array}$

$\mathrm{F}$

F

5

30
3

0,943

9,43

$0,022 \quad 0,24$

$0,008 \quad 0,06$

6,0

F

$\begin{array}{ll}6,0 & 1 \\ & \end{array}$

15455

15458

$\begin{array}{rr}20,0 & 22 \\ & \text { F } \\ 22,0 & 2 \\ & 31 \\ & \text { F } \\ & \text { F } \\ & \text { F } \\ & \text { F }\end{array}$

F

22

13

0,231

1,42

$20,019 \quad 0,13$

$15 \quad 0,404 \quad 2,20$

F

F

F 


\begin{tabular}{|c|c|c|c|c|c|c|}
\hline Famílias/Espécies & $\mathrm{Rg}$ & $\begin{array}{l}\mathrm{h} \\
(\mathrm{m})\end{array}$ & $\mathrm{N}$ & $\mathrm{P}$ & $\begin{array}{l}\mathrm{AB} \\
\left(\mathrm{m}^{2}\right)\end{array}$ & $\mathrm{VC}$ \\
\hline Solanum leucodendron Sendt. & 16298 & 18,0 & 6 & 3 & 0,189 & 0,69 \\
\hline Solanum pseudoquina A. St.-Hil. & 16299 & 15,0 & 4 & 3 & 0,097 & 0,40 \\
\hline Solanum swartzianum Roem. \& Schult. & 15481 & & $\mathrm{~F}$ & & & \\
\hline \multicolumn{7}{|l|}{ STYRACACEAE } \\
\hline Styrax latifolius Pohl & 14581 & 18,0 & 2 & 2 & 0,023 & 0,14 \\
\hline \multicolumn{7}{|l|}{ SYMPLOCACEAE } \\
\hline Symplocos falcata Brand & 15486 & & $\mathrm{~F}$ & & & \\
\hline Symplocos pubescens Klotzsch & 16300 & 18,0 & 2 & 2 & 0,017 & 0,12 \\
\hline \multicolumn{7}{|l|}{ TERNSTROEMIACEAE } \\
\hline Gordonia fruticosa (Schrader) H. Keng. & 16301 & 7,0 & 1 & 1 & 0,005 & 0,05 \\
\hline Ternstroemia brasiliensis Cambess. & 16302 & 10,0 & 2 & 2 & 0,017 & 0,12 \\
\hline \multicolumn{7}{|l|}{ THYMELAEACEAE } \\
\hline Daphnopsis brasiliensis Mart. \& Zucc. & 14196 & 26,0 & 1 & 1 & 0,013 & 0,07 \\
\hline Daphnopsis fasciculata (Meisner) Nevling & 15466 & 12,0 & 9 & 7 & 0,100 & 0,59 \\
\hline \multicolumn{7}{|l|}{ URTICACEAE } \\
\hline Cecropia glaziovii Snethl. & 16403 & 17,0 & 1 & 1 & 0,111 & 0,31 \\
\hline Cecropia hololeuca Miq. & 10290 & & $\mathrm{~F}$ & & & \\
\hline Coussapoa microcarpa (Schott) Rizz. & 16235 & 29,0 & 27 & 15 & 0,904 & 3,26 \\
\hline \multicolumn{7}{|l|}{ VERBENACEAE } \\
\hline Vitex cymosa Bert. & 05635 & 18,0 & 11 & 8 & 0,096 & 0,66 \\
\hline Vitex megapotamica (Sprengel) Moldenke & 14684 & 27,0 & 3 & 2 & 0,250 & 0,73 \\
\hline Vitex polygama Cham. & 15484 & 24,0 & 4 & 4 & 0,230 & 0,72 \\
\hline \multicolumn{7}{|l|}{ VOCHYSIACEAE } \\
\hline Qualea cordata (Mart.) Sprengel & 16303 & 12,0 & 7 & 3 & 0,171 & 0,69 \\
\hline Qualea multiflora Mart. & 16304 & & $\mathrm{~F}$ & & & \\
\hline Vochysia magnifica Warm. & 16306 & 24,0 & 9 & 6 & 0,175 & 0,78 \\
\hline Vochysia tucanorum Mart. & 12590 & 22,0 & 28 & 8 & 0,261 & 1,73 \\
\hline \multicolumn{7}{|l|}{ WINTERACEAE } \\
\hline Drimys brasiliensis Miers & 15489 & & $\mathrm{~F}$ & & & \\
\hline
\end{tabular}

de espécies por área. O valor de $H^{\prime}$ para os Neossolos Regolíticos foi bem inferior aos demais, mas este fato pode estar fortemente influenciado pelo tamanho bem menor da subamostra (duas parcelas).

As três classes de solos diferiram bastante entre si quanto às espécies mais abundantes. As cinco espécies com maior VC nos Cambissolos Húmicos foram Ocotea odorifera, Aspidosperma parvifolium, Nectandra grandiflora, Alchornea triplinervea e Psychotria sessilis; nos Neossolos Litólicos foram Eremanthus erythropappus, Aspidosperma parvifolium, Alchornea triplinervea, Myrsine umbellata e Miconia chartacea; e nos Neossolos Regolítico foram Amaioua guianensis, Aspidosperma parvifolium, Inga sessilis, Ocotea odorifera e Ocotea diospyrifolia (tabela 4). Apenas Aspidosperma parvifolium repete-se nessa posição nas três classes de solo, enquanto Ocotea odorifera e Alchornea triplinervea repetem-se em duas classes de solo.

Os 2.565 indivíduos com DAP $\geq 5 \mathrm{~cm}$ inventariados na amostra (1,2 ha) somaram uma área basal de 40,99 $\mathrm{m}^{2}$ (tabela 5). A densidade média de indivíduos diferiu significativamente entre as classes de solo $(F=9,214$, $P=0,0009)$, sendo a densidade média significativamente maior nos Neossolos Litólicos que nos Cambissolos Húmicos e Neossolos Regolíticos, os quais não diferiram entre si. Por outro lado, a área basal média por hectare não diferiu significativamente entre as classes de solo $(F=0,758, P=0,478)$.

As distribuições da densidade de árvores por classes de altura e diâmetro diferiram claramente entre as três classes de solo (figura 2). A densidade de árvores das duas menores classes de altura $(F=4,977, P=0,014$, para alturas entre 1,3 e 5,0 m; e $F=10,141, P=0,00005$, para alturas entre $>5,0$ e $10 \mathrm{~m})$ e de diâmetro $(F=9,218$, $P=0,0009$, para diâmetros entre 5 e $10 \mathrm{~cm}$; e $F=4,563$, 
Tabela 3. Diversidade de espécies da comunidade arbórea da floresta semidecídua altimontana da chapada das Perdizes, Carrancas, MG: número de indivíduos (Ind) e de espécies (Spp), índice de diversidade de Shannon ( $H^{\prime}$ ) e equabilidade de Pielou ( $J$ ') na amostra total $(N=30$ parcelas de $20 \times 20 \mathrm{~m})$ e nas três classes de solo que a compõem. Para os Cambissolos Húmicos, os valores também foram calculados para uma subamostra aleatória de 10 parcelas para melhor comparação com os Neossolos Litólicos.

Table 3. Species diversity of the tree community of the tropical upper montane semideciduous forest surveyed in the Chapada das Perdizes, Carrancas, SE Brazil: number of individuals (Ind) and species (Spp), Shannon diversity ( $H^{\prime}$ ), and Pielou evenness $\left(J^{\prime}\right)$ in the total sample $(N=3020 \times 20 \mathrm{~m}$ plots $)$ and in the three constituent soil classes. For Humic Cambisols, values were also calculated for a random sub-sample with 10 plots to improve comparisons with Litholic Neosols.

\begin{tabular}{|c|c|c|c|c|c|}
\hline Subgrupos de solos & $N$ & Ind & Spp & $\begin{array}{c}H^{\prime} \\
\text { (nats.ind. }{ }^{-1} \text { ) }\end{array}$ & $J$ \\
\hline Amostra total & 30 & 2565 & 132 & 3,92 & 0,80 \\
\hline Cambissolos Húmicos (total) & 18 & 1381 & 98 & 3,65 & 0,80 \\
\hline Cambissolos Húmicos (subamostra) & 10 & 731 & 81 & 3,66 & 0,83 \\
\hline Neossolos Litólicos & 10 & 1094 & 100 & 3,79 & 0,82 \\
\hline Neossolos Regolíticos & 2 & 90 & 35 & 3,29 & 0,92 \\
\hline
\end{tabular}

$P=0,020$, para diâmetros entre $>10$ e $20 \mathrm{~cm}$ ) diferiram entre as três classes de solo. A densidade de árvores foi significativamente maior nos Neossolos Litólicos que nos outros dois solos para as duas menores classes de altura e para a menor classe de diâmetro. Para a classe de diâmetro entre $>10$ e $20 \mathrm{~cm}$, a densidade de árvores foi significativamente maior nos Neossolos Litólicos que nos Neossolos Regolíticos. Não foram encontradas diferenças significativas entre os três solos para as demais classes de altura e diâmetro.

Distribuição das espécies - Os autovalores da CCA para os dois primeiros eixos de ordenação foram de 0,29 (eixo 1) e 0,10 (eixo 2). O primeiro autovalor pode ser considerado baixo $(<0,5$ sensu ter Braak 1995), indicando a existência de um gradiente curto, ou seja, com poucas substituições de espécies entre os dois extremos e predominância da variação nas abundâncias das espécies. Os dois primeiros eixos explicaram apenas $23,3 \%$ (eixo 1) e 7,8\% (eixo 2) da variância global dos dados (total acumulado: $31,1 \%$ ), indicando muito 'ruído', ou variância remanescente não explicada. Apesar disso, a significância das relações espécie-ambiente não foi prejudicada, pois a CCA produziu altas correlações espécie-ambiente nos dois primeiros eixos: 0,929 (eixo 1) e 0,935 (eixo 2). Além disso, o teste de permutação de Monte Carlo indicou que as abundâncias das espécies e as variáveis ambientais foram significativamente correlacionadas nos dois primeiros eixos de ordenação $(P=0,01)$. As variáveis ambientais mais fortemente correlacionadas com o primeiro eixo foram, em ordem decrescente, $\mathrm{pH}$, classe de drenagem, teor de $\mathrm{P}$ e fator borda e, com o segundo eixo, desnível do terreno, proporção de argila e distância vertical até o riacho. As correlações ponderadas mostram também correlações fortes entre as variáveis, destacando-se aquelas entre a drenagem e borda (positiva) e entre $\mathrm{pH}$ e fósforo e distância vertical e fósforo (ambas negativas).

A ordenação das parcelas no primeiro eixo (figura 3A) sugere claramente uma forte separação entre as parcelas de Cambissolos Húmicos mais Neossolos Regolíticos, aglomeradas à esquerda do diagrama, e as parcelas de Neossolos Litólicos, do lado direito. Percebese ainda que as parcelas de Neossolos Litólicos, que estão bem mais dispersas, separam-se entre as da borda sul, na parte superior do diagrama, e as da borda norte, na parte inferior. As correlações com as sete variáveis ambientais são muito claras no diagrama. Os Neossolos Litólicos vinculam-se ao fator borda mais elevado e à drenagem mais forte, mas os da borda sul mostram-se com maior distância vertical até o riacho, $\mathrm{pH}$ mais elevado e teores mais baixos de $\mathrm{P}$, enquanto os da borda norte têm desnível mais pronunciado e menores teores de argila. Os Cambissolos Húmicos vinculam-se a um fator borda menos elevado e drenagem menos pronunciada. Maiores teores de $\mathrm{P}$ correlacionam-se com as duas parcelas de Neossolos Regolíticos.

A ordenação das espécies pela CCA (figura 3B) sugere que espécies como Eremanthus erythropappus, Clethra scabra, Vochysia tucanorum, Myrcia rostrata, Myrcia guianensis, Ilex conocarpa e Lafoensia pacari tendem a ser mais abundantes nas parcelas de borda e Neossolos Litólicos. A maioria das espécies, como as 18 do aglomerado 1, estão mais fortemente associadas ao interior da floresta. Em posição intermediária surgem 
Tabela 4. Espécies arbóreas com $\geq 10$ indivíduos nas 30 parcelas amostrais de $20 \times 20 \mathrm{~m}$ utilizadas para inventariar a floresta semidecídua altimontana da chapada das Perdizes, Carrancas, MG, seguidas da abreviação utilizada na análise de correspondência canônica (figura 3) e do número de indivíduos e valor de cobertura obtidos nas subamostras correspondentes às três classes de solo: $\mathrm{CHd}=$ Cambissolos Húmicos, $\mathrm{RLh}=$ Neossolos Litólicos, $\mathrm{RRq}=$ Neossolos Regolíticos .

Table 4. Tree species with $\geq 10$ individuals in the $3020 \times 20 \mathrm{~m}$ sample plots used to survey the upper montane semideciduous forest surveyed in the Chapada das Perdizes, Carrancas, SE Brazil, followed by their abbreviations used in the canonical correspondence analysis (figure 3 ) and their number of individuals and cover value obtained in the sub-samples corresponding to the three soil classes: $\mathrm{CHd}=$ Humic Cambisols, $\mathrm{RLh}=$ Litholic Neosols, $\mathrm{RRq}=$ Regolithic Neosols .

\begin{tabular}{|c|c|c|c|c|c|c|c|}
\hline \multirow[t]{2}{*}{ Espécies } & \multirow[t]{2}{*}{ Abreviações } & \multicolumn{3}{|c|}{ Número de indivíduos } & \multicolumn{3}{|c|}{ Valor de cobertura } \\
\hline & & CHd & RLh & $\mathrm{RRq}$ & CHd & RLh & $\mathrm{RRq}$ \\
\hline Alchornea triplinervea & Alch tri & 40 & 41 & 1 & 11,4 & 10,1 & 1,3 \\
\hline Amaioua guianensis & Amai gui & 55 & 7 & 12 & 6,6 & 1,1 & 17,4 \\
\hline Aspidosperma parvifolium & Aspi par & 99 & 51 & 3 & 21,1 & 16,0 & 16,8 \\
\hline Calyptranthes brasiliensis & Caly bra & 11 & 31 & 1 & 1,1 & 4,3 & 2,0 \\
\hline Calyptranthes concinna & Caly con & 39 & 9 & 1 & 3,6 & 1,2 & 3,5 \\
\hline Casearia decandra & Case dec & 18 & 4 & 0 & 2,1 & 0,5 & 0,0 \\
\hline Clethra scabra & Clet sca & 0 & 11 & 0 & 0,0 & 2,3 & 0,0 \\
\hline Cordia sellowiana & Cord sel & 23 & 3 & 3 & 2,9 & 0,7 & 6,7 \\
\hline Coussapoa microcarpa & Cous mic & 25 & 1 & 1 & 4,9 & 0,4 & 4,8 \\
\hline Cupania paniculata & Cupa pan & 14 & 15 & 2 & 1,8 & 2,5 & 5,0 \\
\hline Dalbergia villosa & Dalb vil & 28 & 5 & 0 & 4,5 & 0,7 & 0,0 \\
\hline Eremanthus erythropappus & Erem ery & 0 & 103 & 0 & 0,0 & 26,5 & 0,0 \\
\hline Eugenia hyemalis & Euge hye & 13 & 28 & 5 & 2,1 & 4,8 & 9,7 \\
\hline Geonoma schottiana & Geon sch & 22 & 14 & 6 & 1,8 & 1,5 & 7,2 \\
\hline Guapira opposita & Guap opp & 18 & 37 & 0 & 2,7 & 8,9 & 0,0 \\
\hline Guatteria australis & Guat aus & 15 & 4 & 3 & 2,1 & 0,5 & 7,3 \\
\hline Guatteria nigrescens & Guat nig & 21 & 22 & 2 & 4,6 & 3,3 & 2,8 \\
\hline Ilex conocarpa & Ilex con & 0 & 11 & 0 & 0,0 & 2,2 & 0,0 \\
\hline Inga sessilis & Inga ses & 7 & 2 & 4 & 0,9 & 0,6 & 16,0 \\
\hline Jacaranda subalpina & Jaca sub & 8 & 3 & 0 & 1,4 & 0,7 & 0,0 \\
\hline Lafoensia pacari & Lafo pac & 0 & 15 & 0 & 0,0 & 2,8 & 0,0 \\
\hline Maytenus salicifolia & Mayt sal & 0 & 13 & 0 & 0,0 & 1,8 & 0,0 \\
\hline Miconia chartacea & Mico cha & 49 & 72 & 1 & 4,7 & 9,2 & 1,4 \\
\hline Miconia urophylla & Mico uro & 34 & 22 & 0 & 3,5 & 3,2 & 0,0 \\
\hline Mollinedia argyrogyna & Moll arg & 12 & 20 & 0 & 1,3 & 3,4 & 0,0 \\
\hline Myrcia guianensis & Myrc gui & 0 & 27 & 0 & 0,0 & 3,1 & 0,0 \\
\hline Myrcia rostrata & Myrc ros & 2 & 48 & 0 & 0,2 & 6,1 & 0,0 \\
\hline Myrcia venulosa & Myrc ven & 31 & 12 & 0 & 4,7 & 1,8 & 0,0 \\
\hline Myrciaria floribunda & Myrc flo & 19 & 16 & 2 & 1,6 & 1,8 & 2,4 \\
\hline Myrsine gardneriana & Myrs gar & 10 & 18 & 0 & 0,9 & 2,3 & 0,0 \\
\hline Myrsine umbellata & Myrs umb & 33 & 66 & 1 & 3,6 & 9,2 & 1,2 \\
\hline Nectandra grandiflora & Nect gra & 109 & 23 & 3 & 12,3 & 4,0 & 6,0 \\
\hline Nectandra oppositifolia & Nect opp & 23 & 2 & 3 & 3,9 & 0,2 & 4,4 \\
\hline Ocotea corymbosa & Ocot cor & 29 & 4 & 2 & 6,2 & 0,7 & 7,0 \\
\hline Ocotea diospyrifolia & Ocot dio & 12 & 4 & 2 & 1,7 & 0,5 & 10,8 \\
\hline Ocotea odorifera & Ocot odo & 172 & 24 & 7 & 21,4 & 3,5 & 11,4 \\
\hline Pera glabrata & Pera gla & 21 & 23 & 2 & 4,7 & 4,0 & 4,5 \\
\hline Persea pyrifolia & Pers pyr & 2 & 8 & 0 & 0,2 & 3,4 & 0,0 \\
\hline Prunus myrtifolia & Prun myr & 17 & 4 & 0 & 1,8 & 0,7 & 0,0 \\
\hline Psychotria sessilis & Psyc ses & 115 & 64 & 4 & 10,9 & 8,0 & 5,1 \\
\hline Roupala rhombifolia & Roup rho & 8 & 18 & 0 & 2,4 & 4,2 & 0,0 \\
\hline Schefflera calva & Sche cal & 40 & 22 & 1 & 8,5 & 3,9 & 5,7 \\
\hline Sorocea bonplandii & Soro bon & 10 & 6 & 0 & 1,0 & 0,8 & 0,0 \\
\hline Tapirira obtusa & Tapi obt & 10 & 18 & 0 & 1,4 & 4,5 & 0,0 \\
\hline Tovomitopsis saldanhae & Tovo sal & 16 & 5 & 1 & 2,0 & 1,3 & 1,3 \\
\hline Vitex cymosa & Vite cym & 7 & 4 & 0 & 0,6 & 0,9 & 0,0 \\
\hline Vochysia tucanorum & Voch tuc & 4 & 24 & 0 & 0,4 & 4,0 & 0,0 \\
\hline
\end{tabular}


Tabela 5. Densidade e área basal de árvores (DAP $\geq 5 \mathrm{~cm}$ ) por hectare nas 30 parcelas de $20 \times 20 \mathrm{~m}$ utilizadas para amostrar a floresta semidecídua altimontana da chapada das Perdizes, Carrancas, MG. Os valores são médias \pm desvios padrão da amostra total e das $N$ parcelas das três classes de solo.

Table 5. Density and basal area of trees $(\mathrm{dbh} \geq 5 \mathrm{~cm})$ per hectare in the $3020 \times 20 \mathrm{~m}$ sample plots used to survey the upper montane semideciduous forest of the Chapada das Perdizes, Carrancas, SE Brazil. Values are means \pm standard deviations of the total sample and $N$ plots of the three soil classes.

\begin{tabular}{lrcc}
\hline Classes de solos & $N$ & $\begin{array}{c}\text { Densidade } \\
(\text { árvores.ha }\end{array}$ & $\begin{array}{c}\text { Área basal } \\
\left(\mathrm{m}^{2} \cdot \mathrm{ha}^{-1}\right)\end{array}$ \\
\hline Amostra total & 30 & $2138 \pm 743$ & $34,16 \pm 7,58$ \\
Cambissolos Húmicos & 18 & $1918 \pm 374$ & $32,89 \pm 7,77$ \\
Neossolos Litólicos & 10 & $2735 \pm 884$ & $29,41 \pm 5,02$ \\
Neossolos Regolíticos & 2 & $1125 \pm 318$ & $24,27 \pm 6,95$ \\
\hline
\end{tabular}
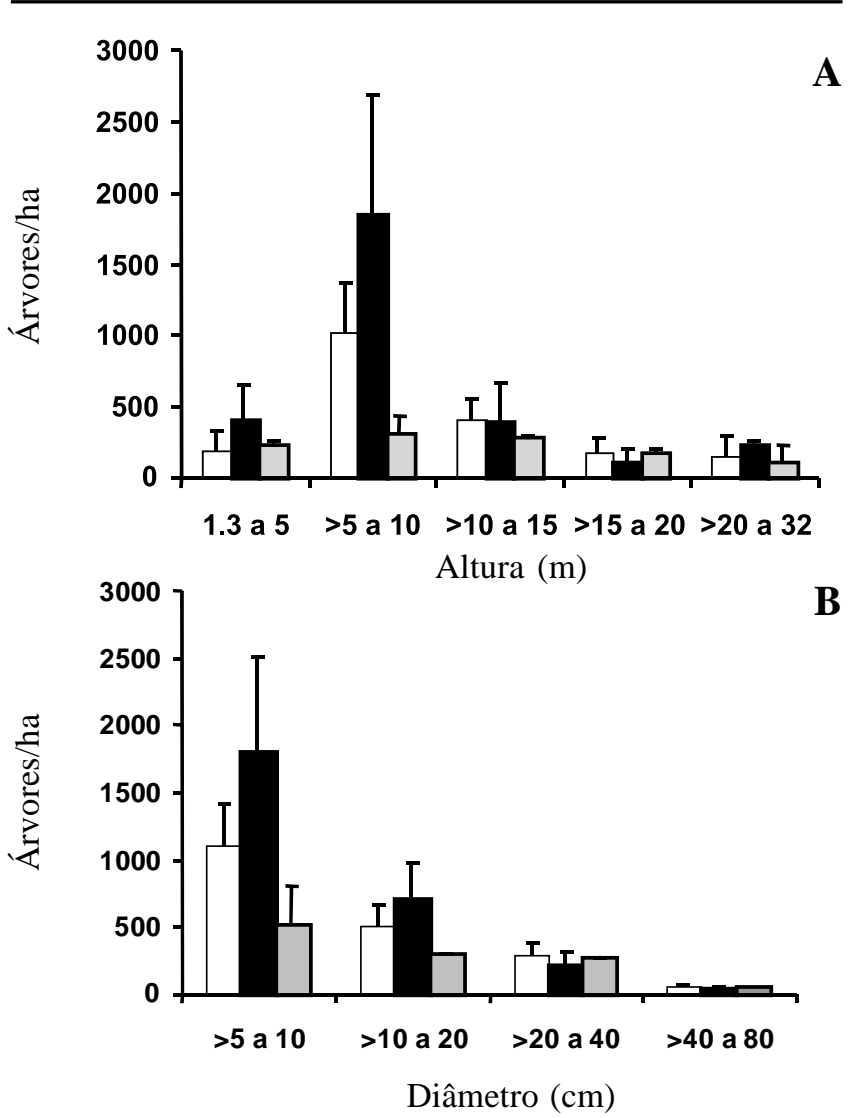

Figura 2. Distribuição da densidade por hectare de árvores com DAP $\geq 5 \mathrm{~cm}$ em classes de altura (A) e diâmetro (B) nas parcelas utilizadas para amostrar a floresta semidecídua alto-montana da chapada das Perdizes, Carrancas, MG, agrupadas nas três classes de solos: Cambissolos $(\square, N=18)$, Neossolos Litólicos $(\boldsymbol{\square}, N=10)$ e Neossolos Regolíticos $(\square, N=2)$. As colunas representam as médias e a linhas verticais as médias + desvios padrão. espécies como Pera glabrata, Myrsine umbellata, Calyptranthes brasiliensis, Tapirira obtusa e Roupala rhombifolia.

\section{Discussão}

Perfil e contexto florístico - O perfil florístico da comunidade arbórea da floresta semidecídua altomontana do presente estudo, doravante referida apenas como Mata de Carrancas, diferencia-se em muito daqueles encontrados em levantamentos de outras áreas de florestas na região situadas em altitudes mais baixas, entre 800 e 1.000 m (e.g. Oliveira Filho et al. 1994b, Carvalho et al. 1995b, van den Berg \& Oliveira Filho 2000, Vilela et al. 2000, Botrel et al. 2002, EspíritoSanto et al. 2002, Rodrigues et al. 2003, Souza et al. 2003). Famílias aqui destacadas pelo maior número de espécies, como Aquifoliaceae, Asteraceae, Clusiaceae, Cyatheaceae e Myrsinaceae, não apresentam tal importância nestas outras áreas. Já a família Fabaceae, de maneira inversa, exibe na Mata de Carrancas pequena expressão, ao passo que mostra grande importância nas áreas levantadas em menores altitudes, juntamente com as famílias Myrtaceae, Rubiaceae, Lauraceae, Melastomataceae e Euphorbiaceae. Mesmo para algumas dessas famílias, como Myrtaceae, Melastomataceae e Lauraceae, a Mata de Carrancas se diferencia regionalmente pela maior riqueza em espécies bem como pelo elevado número de indivíduos amostrados em relação às matas estudadas em altitudes mais baixas.

Esse perfil florístico assemelha-se ao encontrado por Oliveira Filho \& Fontes (2000) para as Florestas Atlânticas Alto-montanas, tanto ombrófilas como semidecíduas. Gentry (1995), analisando florestas Andinas e da América Central, observou a perda de importância da família Fabaceae a partir dos $1.500 \mathrm{~m}$ de altitude, enquanto aumenta o predomínio de Lauraceae, Melastomataceae e Rubiaceae. A essa observação, Oliveira Filho \& Fontes (2000) acrescentaram Asteraceae e Myrsinaceae para o

Figure 2. Distribution of the density per hectare of trees with $\mathrm{dbh} \geq 5 \mathrm{~cm}$ into classes of height (A) and diameter (B) in the plots used to sample an area of tropical upper montane semideciduous forest in the Chapada das Perdizes, Carrancas, SE Brazil, grouped into three soil classes: Cambisols $(\square, N=18)$, Litholic Neosols ( $\square, N=10$ ), Regolithic Neosols $(\square, N=2)$. Columns represent arithmetic means and vertical lines means + standard deviations. 


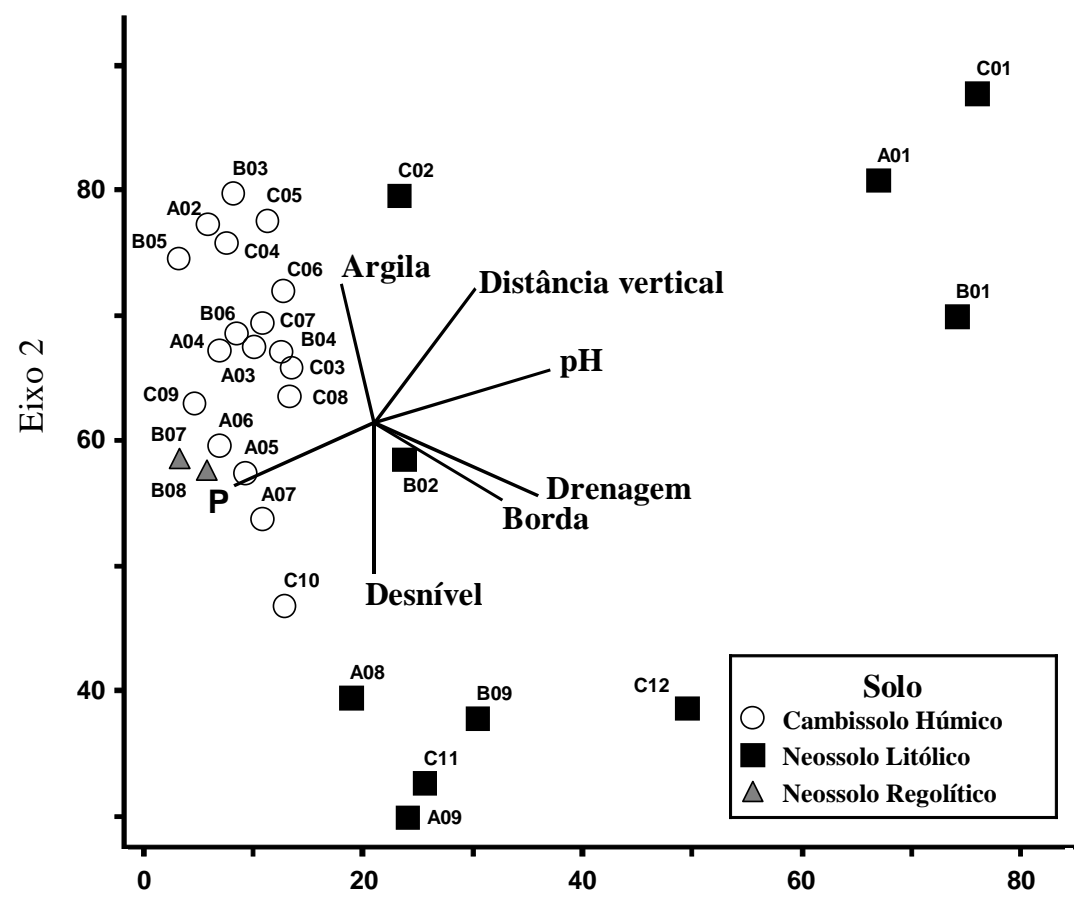

A

Eixo 1

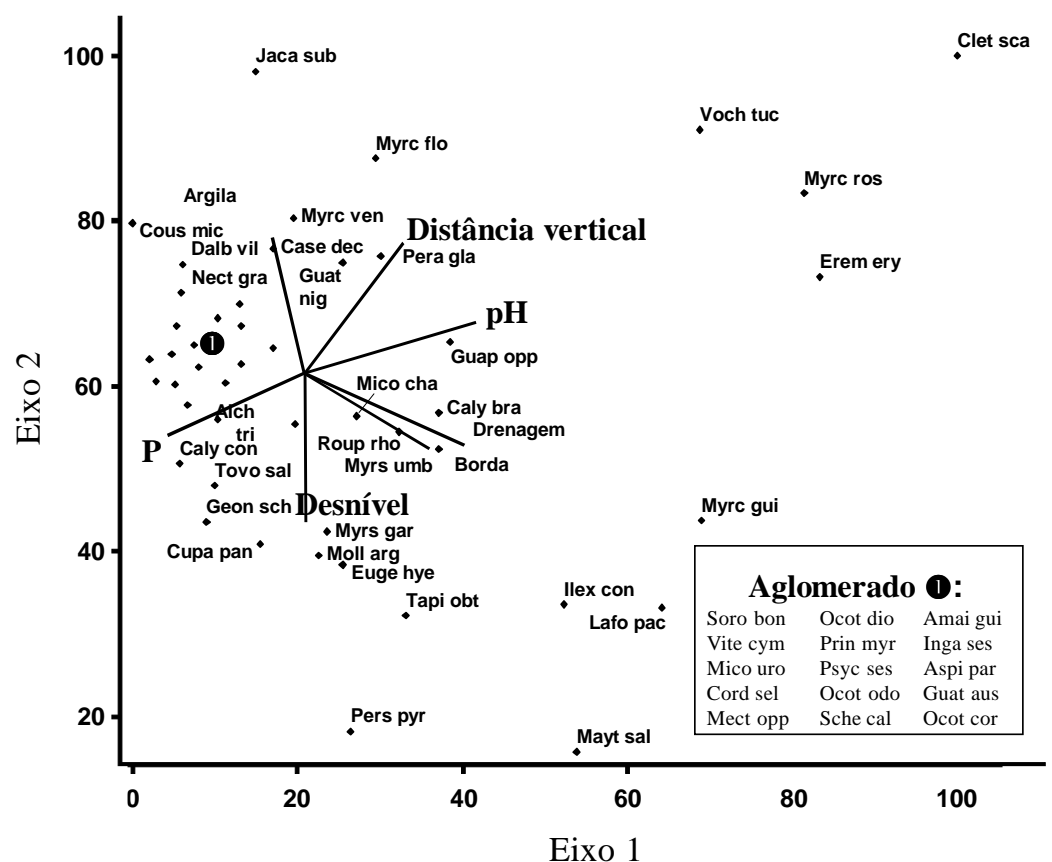

Figura 3. Análise de correspondência canônica: diagrama de ordenação das parcelas (A) e espécies (B) baseada na distribuição do número de indivíduos de 47 espécies em 30 parcelas de floresta semidecídua alto-montana da chapada das Perdizes, Carrancas, MG, e sua correlação com as sete variáveis ambientais utilizadas (retas). As parcelas são identificadas pela transeção mais número de ordem (vide figura 1B) e classificadas nas três classes de solo. As espécies são indicadas pelo seu nome abreviado (correspondência com nomes completos na tabela 2).

Figure 3. Canonical correspondence analysis: ordination diagrams for plots (A) and species (B) based on the distribution of the number of individuals of 47 species in 30 plots of tropical upper montane semideciduous forest in the Chapada das Perdizes, Carrancas, SE Brazil, and their correlation with the seven environmental variables used (arrows). The plots are identified by their transect and rank number (see figure 1B) and classified into three soils classes. The species are indicated by their abbreviated names (correspondence with full names in table 2). 
Tabela 6. Análise de correspondência canônica (CCA): correlações internas ( 'intraset') nos dois primeiros eixos de ordenação e matriz de correlações ponderadas para as variáveis ambientais utilizadas na análise. Correlações com valores absolutos > 0,5 estão indicadas em negrito.

Table 6. Canonical correspondence analysis (CCA): intraset correlations in the first two ordination axes and weighted correlation matrix for the environmental variables used in the analysis. Correlations with absolute values $>0.5$ area indicated in bold.

\begin{tabular}{|c|c|c|c|c|c|c|c|c|}
\hline \multirow[t]{2}{*}{ Variáveis ambientais } & \multicolumn{2}{|c|}{ Correlações ponderadas } & \multirow[t]{2}{*}{ Drenagem } & \multirow[t]{2}{*}{$\mathrm{pH}$} & \multirow[t]{2}{*}{$\mathrm{P}$} & \multirow[t]{2}{*}{ Argila } & \multirow[t]{2}{*}{ Desnível } & \multirow[t]{2}{*}{ Borda } \\
\hline & Eixo 1 & Eixo 2 & & & & & & \\
\hline Drenagem & 0,745 & $-0,368$ & - & & & & & \\
\hline $\mathrm{pH}$ & $\mathbf{0 , 8 0 1}$ & 0,262 & 0,460 & - & & & & \\
\hline $\mathrm{P}$ & $-0,632$ & $-0,323$ & $-0,388$ & $-0,605$ & - & & & \\
\hline Argila & $-0,142$ & $\mathbf{0 , 7 0 5}$ & $-0,233$ & $-0,038$ & $-0,347$ & - & & \\
\hline Desnível & $-0,001$ & $-0,772$ & 0,407 & $-0,128$ & 0,354 & $-0,580$ & - & \\
\hline Borda & $\mathbf{0 , 5 8 0}$ & $-0,389$ & 0,708 & 0,354 & $-0,254$ & $-0,323$ & 0,329 & - \\
\hline Distância vertical & 0,455 & 0,681 & 0,258 & 0,481 & $-0,651$ & $\mathbf{0 , 5 9 0}$ & $-0,544$ & 0,161 \\
\hline
\end{tabular}

Sudeste do Brasil. Das 65 espécies apontadas por esses autores como indicadoras de Florestas Atlânticas Altomontanas, 41 (ou 63\%) ocorreram na Mata de Carrancas. Espécies indicadoras das outras formações florestais apontadas pelos autores aparecem na Mata de Carrancas em número bastante reduzido. Entre os gêneros mais ricos em espécies encontrados na Mata de Carrancas, Miconia e Ilex são considerados por Webster (1995) como característicos de florestas nebulares neotropicais, além de outros que aí ocorreram como Cyathea, Clethra, Clusia, Drimys, Ficus, Gordonia, Meliosma, Podocarpus, Prunus, Rhamnus, Roupala, Ternstroemia e Weinmannia. No mesmo sentido, as famílias mais ricas na área, Melastomataceae e Myrtaceae, também são consideradas pelo autor como características dessas florestas, além de outras aí encontradas como Aquifoliaceae, Clethraceae, Clusiaceae, Cunoniaceae, Elaeocarpaceae, Magnoliaceae, Podocarpaceae, Rhamnaceae, Rosaceae, Sabiaceae, Styracaceae, Symplocaceae e Winteraceae. Tal observação reforça o caráter alto-montano como diferenciador da Mata de Carrancas na região. A influência da altitude na diferenciação florística entre florestas semidecíduas foi demonstrada por Salis et al. (1995), para o estado de São Paulo, e por Oliveira Filho \& Fontes (2000), para o sudeste brasileiro. A Mata de Carrancas ainda apresenta uma peculiaridade fisionômica citada por Gentry (1995) como característica das florestas altomontanas neotropicais, que é a abundância de epífitas, sobretudo de bromélias, orquídeas, pteridófitas, musgos e líquens. Uma espécie de Aechmea (Bromeliaceae) recobria o piso floresta na maioria das áreas bem drenadas do interior.

Diversidade, estrutura e distribuição das espécies - O número de espécies encontrado (217) pode ser considerado intermediário quando comparado a outros levantamentos realizados em florestas protetoras de nascentes da região, como os dois de Itutinga (van den Berg \& Oliveira Filho 2000, Vilela et al. 1995) e o do Poço Bonito, em Lavras (Oliveira Filho et al. 1994a), com 253, 162 e 219 espécies, respectivamente. Em outros levantamentos em fragmentos localizados ao longo de cursos de rios na região, Gavilanes et al. (1992), no município de Madre de Deus de Minas, encontrou 170 espécies; Carvalho et al. (1995a), em Bom Sucesso, 245; Botrel et al. (2002), em Ingaí, 211; e Souza et al. (2003), em Lavras, 165. Todos estes levantamentos adotaram o DAP mínimo de $5 \mathrm{~cm}$ e apresentam amostragens de tamanhos semelhantes.

$O$ índice de Shannon encontrado (3,92 nats.indivíduo-1) também apresenta-se intermediário entre os levantamentos acima citados. Para as matas protetoras de nascentes, 3,90 e 3,92 em Itutinga e 4,20 em Lavras. Para as matas ao longo de rios, 3,76 em Madre de Deus de Minas, 4,33 em Bom Sucesso, 3,73 em Ingaí e 4,26 em Lavras. O mesmo pode ser observado para o índice de eqüabilidade de Pielou encontrado $(0,80)$, que varia de 0,75 a 0,88 nas matas protetoras de nascentes citadas e de 0,76 a 0,86 naquelas ao longo dos rios. Esses valores indicam que há concentração de abundâncias em algumas espécies, ou seja, dominância ecológica, fato comum em florestas tropicais (Richards 1952). 
A área de Cambissolos Húmicos, onde foi encontrada uma menor diversidade de espécies, corresponde ao interior da floresta, onde os solos são bem drenados. Já as áreas de Neossolos Litólicos, com maior diversidade, correspondem às bordas da floresta, onde o terreno é fortemente drenado e declivoso. Todos esses fatores, associados aos efeitos de borda, aumentam a perda de umidade no solo, como já apontado por Bierregard et al. (1992), Camargo \& Kapos (1995), Murcia (1995) e Kapos et al. (1997), o que também pode favorecer a ocorrência de incêndios, bastante comuns neste tipo de ambiente (campos de altitude), como na maioria das paisagens savânicas tropicais (Werner 1991, Furley et al. 1992).

$\mathrm{Na}$ Mata de Carrancas, a borda e o interior da mata apresentaram diferentes conjuntos de espécies principais, sendo a primeira caracterizada pela grande abundância de Eremanthus erythropappus, ou candeia. Nas regiões montanhosas do Sudeste do Brasil, o nome candeal é dado a essa fisionomia florestal de estatura mais baixa (6 a $12 \mathrm{~m}$ de altura) e com predominância da candeia. De acordo com Oliveira Filho \& Fluminhan Filho (1999), o candeal surge normalmente nas áreas de transição entre florestas e campos de altitude, onde os solos tornam-se gradualmente mais rasos. Os autores salientam ainda que o candeal forma uma área tampão contra os incêndios, sendo seus limites afetados pela frequiência e intensidade dos mesmos.

O fogo, em si, poderia ser apontado como um possível agente de incremento da heterogeneidade ambiental e, dessa forma, provocador de uma maior diversidade nas bordas. Porém, observa-se também o fato das bordas diferirem bastante entre si em suas características ambientais e, conseqüentemente, em seus repertórios de espécies. Apesar de ambas estarem sobre Neossolos Litólicos, diferem em acidez, fertilidade e textura, além de diferirem também topograficamente. Assim, evidencia-se uma maior heterogeneidade natural nos ambientes de borda, onde atuam diferentes combinações de variáveis. Tal situação também reforça a importância do cuidado nos desenhos amostrais para pesquisa dessas comunidades. De maneira semelhante às florestas ripárias, onde comumente existe alta heterogeneidade espacial e ambiental (Oliveira Filho et al. 1990, Jacomine 2000), os candeais marginais às florestas alto-montanas talvez componham um efeito tampão mais complexo em relação ao proposto inicialmente por Oliveira Filho \& Fluminhan Filho (1999).

A densidade de árvores encontrada na Mata de Carrancas, de 2.138 árvores.ha $^{-1}$, situa-se entre as mais elevadas (quinta posição) registradas em 20 levantamentos realizados na região do Alto Rio Grande utilizando o mesmo diâmetro mínimo e que variam de 2.683 árvores.ha $^{-1}$, em Ingaí, a 969 árvores.ha $^{-1}$, em Ibituruna (Pereira 2003). Quanto à área basal, que foi de 34,16 $\mathrm{m}^{2}$.ha ${ }^{-1}$, a Mata de Carrancas também apresentou valores elevados em relação às outras áreas, ocupando a quarta posição de uma amplitude que variou de 42,37 $\mathrm{m}^{2}$.ha-1, em Piedade do Rio Grande, a 19,79 $\mathrm{m}^{2} \cdot \mathrm{ha}^{-1}$, em Tiradentes (Pereira 2003). Estes valores indicam densidade e biomassa relativamente elevadas em relação à maioria das matas da região. Diferenças entre essas florestas relacionadas ao histórico de distúrbios, efeito borda, estoque de nutrientes minerais e regime de água no solo podem estar vinculadas a esses padrões, o que requer estudos comparativos mais precisos para permitir inferências mais seguras. A maior densidade de indivíduos nas bordas que no interior da floresta, sobretudo para os de menor diâmetro e altura, provavelmente resulta de uma estrutura e dinâmica que são particulares de ambientes com regimes de água e de luz bastante distintos, o que já foi detectado para outras bordas naturais na região por van den Berg \& Oliveira Filho (1999) e Oliveira Filho et al. (1994a), bem como para bordas de origem antrópica por Oliveira Filho et al. (1997).

Agradecimentos - Este trabalho integrou o Subprojeto 'Estratégias para conservação e manejo da biodiversidade em fragmentos de florestas semidecíduas' executado pela Embrapa Recursos Genéticos, a Universidade Federal de Lavras e Universidade de Brasília e integrante do Projeto de Conservação e Utilização Sustentável da Diversidade Biológica Brasileira (Probio). Agradecemos aos proprietários da área, Sr. Mário Bernardino Silva (Fazenda Chapada das Perdizes) e Sr. Ivo Antônio Ferreira (Fazenda Mata da Arapuca), por permitirem a realização deste estudo, e aos alunos e professores da UFLA; Enivanis de Abreu Vilela, Joema Rodrigues Póvoa, José Aldo Alves Pereira, Lucas Guida, Luciana Botezelli, Vagner Fernandes Silva e Yule Roberta Ferreira Nunes pelo auxílio nos trabalhos de campo.

\section{Referências bibliográficas}

APG II. 2003. An update of the Angiosperm Phylogeny Group classification for the orders and families of flowering plants: APG II. Botanical Journal of the Linnaean Society 141:399-436.

BIERREGAARD, R.O., LOVEJOY, T.E., KAPOS, V., SANTOS, A.A. \& HUTCHINGS, R.N. 1992. The biological dynamics of tropical rain forest fragments. Bioscience 42:859-866. 
BOTREL, R.T., OLIVEIRA FILHO, A.T., RODRIGUES, L.A. \& CURI, N. 2002. Influência do solo e topografia sobre as variações da composição florística e estrutura da comunidade arbóreo-arbustiva de uma floresta estacional semidecidual em Ingaí, MG. Revista Brasileira de Botânica 25:195-213.

BROWER, J.E. \& ZAR, J.H. 1984. Field and laboratory methods for general ecology. W.M.C. Brow, Dubuque.

CAMARGO, J.L.C. \& KAPOS, V. 1995. Complex edge effects on soil moisture and microclimate in Central Amazonian Forest. Journal of Tropical Ecology 11:208-211.

CARVALHO, D.A., OLIVEIRA FILHO, A.T., VILELA, E.A. \& GAVILANES, M.L. 1995a. Estrutura fitossociológica de mata ripária do alto Rio Grande (Bom Sucesso/MG). Revista Brasileira de Botânica 18:39-49.

CARVALHO, D.A., OLIVEIRA FILHO, A.T., VILELA, E.A. \& GAVILANES, M.L. 1995b. Flora arbustivoarbórea de uma floresta ripária no alto Rio Grande em Bom Sucesso, MG. Acta Botanica Brasilica 9:231-245.

COSTA, C.M.R., HERRMANN, G., MARTINS, C.S., LINS, L.V. \& LAMAS, I.R. (org.). 1998. Biodiversidade em Minas Gerais: um atlas para sua conservação. Fundação Biodiversitas, Belo Horizonte.

EMBRAPA. 1997. Manual de métodos de análises de solo. 2 ed. Empresa Brasileira de Pesquisa Agropecuária, Centro Nacional de Pesquisa de Solos, Rio de Janeiro.

EMBRAPA. 1999. Sistema brasileiro de classificação de solos. Empresa Brasileira de Pesquisa Agropecuária, Centro Nacional de Pesquisa de Solos, Rio de Janeiro.

ESPÍRITO-SANTO, F.D.B., OLIVEIRA FILHO, A.T., MACHADO, E.L.M., SOUZA, J.S., FONTES, M.A.L. \& MARQUES, J.J.G.S.M. 2002. Variáveis ambientais e a distribuição de espécies arbóreas em um remanescente de Floresta Estacional Semidecídua Montana no campus da Universidade Federal de Lavras, MG. Acta Botanica Brasilica 16:331-356.

FURLEY, P.A., PROCTOR, J. \& RATTER, J.A. 1992. Nature and dyanmics of forest-savanna boundaries. Chapman \& Hall, London.

GAVILANES, M.L., OLIVEIRA FILHO, A.T., CARVALHO, D.A. \& VILELA, E.A. 1992. Flora arbustivo-arbórea de uma mata ciliar do alto Rio Grande em Madre de Deus de Minas/MG. Daphne 2:15-24.

GENTRY, A.H. 1995. Patterns of diversity and floristic composition in neotropical montane forests. In Biodiversity and conservation of neotropical montane forests: Proceedings of neotropical montane forest biodiversity and conservation Symposium (S.P. Churchill, H. Balslev, E. Forero \& J.L. Luteyn, eds.). The New York Botanical Garden, New York, p.103-126.

JACOMINE, P.K.T. 2000. Solos sob matas ciliares. In Matas ciliares: conservação e recuperação (R.R. Rodrigues \& H.F. Leitão Filho, eds.). Edusp, São Paulo, p.27-31.
KAPOS, V., CAMARGOS, J.L.C. \& DANDE, G. 1997. Edge related changes in environment and plant response due to forest fragmentation in Central Amazonia. In Tropical forest remnants: ecology, management and conservation of fragmented communities (W.F. Laurance \& R.O. Bierregaard, eds.) The University of Chicago Press, Chicago, p.45-54.

MCCUNE, B. \& MEFFORD, M.J. 1999. PC-ORD version 4.0., multivariate analysis of ecological data, Users guide. MjM Software Design, Glaneden Beach.

MURCIA, C. 1995. Edge effects in fragmented forest: implications for conservation. Trends in Ecology and Evolution 10:58-62.

OLIVEIRA FILHO, A.T., RATTER, J.A. \& SHEPHERD, G.J. 1990. Floristic composition and community structure of a central Brazilian gallery forest. Flora 184:103-117.

OLIVEIRA FILHO, A.T., ALMEIDA, R.J., MELLO, J.M. \& GAVILANES, M.L. 1994a. Estrutura fitossociológica e variáveis ambientais em um trecho da mata ciliar do córrego dos Vilas Boas, Reserva Biológica do Poço Bonito, Lavras (MG). Revista Brasileira de Botânica 17:67-85.

OLIVEIRA FILHO, A.T., VILELA, E.A., CARVALHO, D.A. \& GAVILANES, M.L. 1994b. Differentiation of streamside and upland vegetation in an area of montane semideciduous forest in southeastern Brazil. Flora 189:1-19.

OLIVEIRA FILHO, A.T., VILELA, E.A., GAVILANES, M.L. \& CARVALHO, D.A. 1994c. Comparison of the woody flora and soils of six areas of montane semideciduous forest in Southern Minas Gerais, Brazil. Edinburgh Journal of Botany 51:335-389.

OLIVEIRA FILHO, A.T., VILELA, E.A., CARVALHO, D.A. \& GAVILANES, M.L. 1994d. Effects of soils and topography on the distribution of tree species in a tropical riverine forest in south-eastern Brazil. Journal of Tropical Ecology 10:483-508.

OLIVEIRA FILHO, A.T., VILELA, E.A., GAVILANES, M.L. \& CARVALHO, D.A. 1994e. Effect of flooding regime and understorey bamboos on the physiognomy and tree species composition of a tropical semideciduous forest in Southeastern Brazil. Vegetatio 113:99-124.

OLIVEIRA FILHO, A.T., MELLO, J.M. \& SCOLFORO, J.R.S. 1997. Effects of past disturbance and edges on tree community structure and dynamics within a fragment of tropical semideciduous forest in southeastern Brazil over a five-year period (1987-1992). Plant Ecology 131:45-66.

OLIVEIRA FILHO, A.T. \& FLUMINHAN FILHO, M. 1999. Ecologia da vegetação do Parque Florestal Quedas do Rio Bonito. Cerne 5:51-64.

OLIVEIRA FILHO, A.T. \& FONTES, M.A.L. 2000. Patterns of floristic differentiation among Atlantic forests in Southeastern Brazil and the influence of climate. Biotropica 32:793-810. 
OLIVEIRA FILHO, A.T., CURI, N., VILELA, E.A. \& CARVALHO, D.A. 2001. Variation in tree community composition and structure with changes in soil properties within a fragment of semideciduous forest in south-eastern Brazil. Edinburgh Journal of Botany 58:139-158.

PEREIRA, J.A.A. 2003. Efeitos dos impactos ambientais e da heterogeneidade ambiental sobre a diversidade e estrutura da comunidade arbórea de 20 fragmentos de florestas semidecíduas da região do Alto Rio Grande, Minas Gerais. Tese de doutorado, Universidade Federal de Minas Gerais, Belo Horizonte.

RICHARDS, P.W. 1952. The tropical rain forest. Cambridge University Press, Cambridge.

RODRIGUES, R.R. 1988. Métodos fitossociológicos mais usados. Casa da Agricultura 10:20-24.

RODRIGUES, L.A., CARVALHO, D.A., OLIVEIRA FILHO, A.T., BOTREL, R.T. \& SILVA, E.A. 2003. Florística e estrutura da comunidade arbórea de um fragmento florestal em Luminárias, MG. Acta Botanica Brasilica 17:71-97.

ROBIM, M.J., PASTORE, J.A., AGUIAR, O.T. \& BAITELLO, J.B. 1990. Flora arbóreo arbustiva e herbácea do Parque Estadual de Campos do Jordão (SP). Revista do Instituto Florestal 2:31-53.

SALIS, S.M., SHEPHERD, G.J. \& JOLY, C.A. 1995. Floristic comparison of mesophytic semideciduous forests of the interior of the state of São Paulo, Southeast Brazil. Vegetatio 119:155-164.

SOUZA, J.S., ESPÍRITO-SANTO, F.D.B., FONTES, M.A.L., OLIVEIRA FILHO, A.T. \& BOTEZELLI, L. 2003. Análise das variações florísticas e estruturais da comunidade arbórea de um fragmento de Floresta Semidecídua às margens do rio Capivari, Lavras-MG. Revista Árvore 27:185-206.

TER BRAAK, C.J.F. 1987. The analysis of vegetationenvironment relationship by canonical correspondence analysis. Vegetatio 69:69-77.

TER BRAAK, C.J.F. 1995. Ordination. In Data analysis in community and landscape ecology (R.H.G. Jongman, C.J.F. ter Braak \& O.F.R. van Tongeren, eds.). Cambrigde University Press, Cambrigde, p.91-173.
VAN DEN BERG, E. \& OLIVEIRA FILHO, A.T. 1999. Spatial partitioning among tree species within an area of tropical montane gallery forest in south-eastern Brazil. Flora 194:249-246.

VAN DEN BERG, E. \& OLIVEIRA FILHO, A.T. 2000. Composição florística e estrutura fitossociológica de uma floresta ripária em Itutinga, MG, e comparação com outras áreas. Revista Brasileira de Botânica 23:231-253.

VELOSO, H.P., RANGEL FILHO, A.L.R. \& LIMA, J.C.A. 1991. Classificação da vegetação brasileira adaptada a um sistema universal. Instituto Brasileiro de Geografia e Estatística, Rio de Janeiro.

VILELA, E.A., OLIVEIRA FILHO, A.T., CARVALHO, D.A. \& GAVILANES, M.L. 1994. Fitossociologia e fisionomia de mata semidecídua margeando o reservatório de Camargos em Itutinga, Minas Gerais. Ciência e Prática 18:408-414.

VILELA, E.A., OLIVEIRA FILHO, A.T., CARVALHO, D.A. \& GAVILANES, M.L. 1995. Flora arbustivoarbórea de um fragmento de mata ciliar no alto rio Grande, Itutinga, Minas Gerais. Acta Botanica Brasilica 9:87-100.

VILELA, E.A., OLIVEIRA FILHO, A.T., CARVALHO, D.A., GUILHERME, F.A.G. \& APPOLINÁRIO, V. 2000. Caracterização estrutural de floresta ripária do Alto Rio Grande, em Madre de Deus de Minas, MG. Cerne 6:41-54.

WEBSTER, G.L. 1995. The panorama of neotropical cloud forests. In Biodiversity and conservation of neotropical montane forests: Proceedings of neotropical montane forest biodiversity and conservation symposium (S.P. Churchill, H. Balslev, E. Forero \& J.L. Luteyn, eds.). The New York Botanical Garden, New York, p.53-77.

WERNER, P.A. 1991. Savanna ecology and management, Australian perspectives and intercontinental comparisons. Blackwell, London.

ZAR, J.H. 1996. Biostatistical analysis, Prentice Hall, New Jersey. 